IZA DP No. 5701

Impact of Rural Employment Guarantee Schemes on Seasonal Labor Markets:

Optimum Compensation and Workers' Welfare

Arnab K. Basu

May 2011 


\title{
Impact of Rural Employment Guarantee Schemes on Seasonal Labor Markets: Optimum Compensation and Workers' Welfare
}

\author{
Arnab K. Basu \\ College of William \& Mary, \\ ZEF, University of Bonn and IZA
}

Discussion Paper No. 5701

May 2011

IZA

P.O. Box 7240

53072 Bonn

Germany

Phone: +49-228-3894-0

Fax: +49-228-3894-180

E-mail: iza@iza.org

Any opinions expressed here are those of the author(s) and not those of IZA. Research published in this series may include views on policy, but the institute itself takes no institutional policy positions.

The Institute for the Study of Labor (IZA) in Bonn is a local and virtual international research center and a place of communication between science, politics and business. IZA is an independent nonprofit organization supported by Deutsche Post Foundation. The center is associated with the University of Bonn and offers a stimulating research environment through its international network, workshops and conferences, data service, project support, research visits and doctoral program. IZA engages in (i) original and internationally competitive research in all fields of labor economics, (ii) development of policy concepts, and (iii) dissemination of research results and concepts to the interested public.

IZA Discussion Papers often represent preliminary work and are circulated to encourage discussion. Citation of such a paper should account for its provisional character. A revised version may be available directly from the author. 


\section{ABSTRACT \\ Impact of Rural Employment Guarantee Schemes on Seasonal Labor Markets: Optimum Compensation and Workers' Welfare*}

The recent enactment of the National Rural Employment Guarantee Act in India has been widely hailed a policy that provides a safety net for the rural poor with the potential to boost rural income, stabilize agricultural production and reduce rural-urban migration. This paper, models the impact of such employment guarantee schemes in the context of an agrarian economy characterized by lean season involuntary unemployment as a consequence of tiedlabor contracts. Specifically, we examine labor and output market responses to a productive rural Employment Guarantee Scheme (EGS) and determine the optimal compensation to public work employees consistent with the objectives of (i) productive efficiency in agriculture and (ii) welfare maximization of the laborers. Our framework provides a theoretical framework for the evaluation of a number of (sometimes) conflicting observations and empirical results on the impact of an EGS on agricultural wages, employment and output, and underscores the importance of the relative productivity of workers in the EGS program vis-à-vis their counterparts engaged in agricultural production in determining the success of these programs.

JEL Classification: J3, Q38, Q12

Keywords: labor contracts, rural unemployment, employment guarantee schemes, public input, optimal wage

Corresponding author:

Arnab K. Basu

Department of Economics

College of William \& Mary

Williamsburg, VA 23185

USA

E-mail: akbasu@wm.edu

\footnotetext{
* Research support from the Alexander von Humboldt Foundation, Germany and the Freeman Grant from the Reves Center at the College of William and Mary is gratefully acknowledged. I thank three anonymous referees for their comments and Iryna Dovgel for able research assistance. Part of the research was completed while the author was visiting the School of Industrial and Labor Relations, Cornell University, and special thanks to Gary Fields for his hospitality and insightful observations on the structure of labor markets in developing countries.
} 


\section{Introduction}

Guaranteed employment at a pre-determined wage aimed at providing income security to the otherwise unemployed has been a longstanding staple policy for governments worldwide. Starting with the Poor Employment Act of 1817 in Britain, and later on the New Deal Programs in the United States in the 1930s, government intervention in the labor market as an employer of the last resort has been adopted as an integral feature of labor market policies in many developing countries over the last few decades (Lipton, 1996). Recent examples of the latter include public work programs in India, Bangladesh, Pakistan, Philippines, Egypt, Botswana, Kenya and Chile (Subbarao, 1999; Lipton, 1996).

Amongst developing countries, no public works program has been empirically studied as extensively as the Employment Guarantee Scheme (EGS) in the State of Maharashtra, India ${ }^{1}$. It is not surprising, therefore, that the recent enactment of the National Rural Employment Guarantee Act of India in 2005 (since renamed the The Mahatma Gandhi National Rural Employment Guarantee Act) has generated renewed interest in the effectiveness of EGS programs to provide an economic safety net to the rural poor. The National Rural Employment Guarantee Scheme (NREGS) following the Act of 2005 has, with minor modifications, broadened the coverage and enacted into law the EGS in existence since the 1960's in the State of Maharashtra in India. In turn, the origins of the Maharashtra EGS in India and its' counterpart, the Rural Public Works (RPW) program in Bangladesh can be traced back to the Famine Codes established in British India in the 1880's where direct action in the form of public work programs was the central feature of famine relief strategy.

It is now widely recognized that labor market interventions through rural EGS programs generate both income support for the poor as well as raise agricultural productivity over the long run (Drèze, 1990). As examples, the EGS in Maharashtra has been credited with averting a famine during the drought of 1970 - 73, and alleviating poverty (Drèze, 1990 and Dandekar, 1986) while the Rural Public Works (RPW) program in Bangladesh has been commended for its contribution to rural development and increased agricultural production through the creation and maintenance of rural infrastructure (Alamgir, 1983). In this context, the NREGS can be thought of as a policy to boost rural income, stabilize agricultural production and reduce rural-urban migration.

\footnotetext{
${ }^{1}$ See for example, Ravallion (1990 \& 1991), Ravallion, Datt and Chaudhuri (1993).
} 
The NREGS is initially applicable in 200 rural districts and encompass all rural areas of India including the Fifth and Sixth Schedule areas, except the State of Jammu and Kashmir. Some of the provisions of the NREGS are: (i) every household in the rural areas of India shall have a right to at least 100 days of guaranteed employment every year for at least one adult member for doing casual manual labour at the rate of Rupees 60 per day (approximately US $\$ 1.30$ per day); (ii) only productive works shall undertaken: the identification of projects will be based on the economic, social and environmental benefits of different types of works, their contribution to social equity, and their ability to create permanent assets; and (iii) employment will be provided within a radius of 5 kilometers of the village where the applicant resides at the time of applying. Moreover, the NREGS allows for any existing EGS to be deemed as the action plan for purposes of the Act. Existing EGS programs, however, have stricter workfare guidelines as compared to the broader scope of the NREGS elucidated above. For instance, the EGS in Maharashtra specifies that (a) large scale employment is to be provided to landless laborers during the lean (or slack) seasons, thereby preventing the out-migration of laborers to the urban regions, (b) construct and maintain rural infrastructure, viz, irrigation facilities, flood control measures and roads, (c) encourage farmers to invest in cultivation so as to fulfill the objective of self-sufficiency in foodgrains, and (d) public works employment should not affect the availability of agricultural labor at lawful minimum wages (Dandekar and Sathe, 1980).

Although the design and efficacy of public works programs as an instrument for poverty alleviation has been a subject of extensive theoretical research ${ }^{2}$, the effect of such programs on rural labor market outcomes and agricultural production decisions has received surprisingly little attention. Notable exceptions to the latter has been the work of Ravallion (1990) and Khan (1993), which recognizes that EGS programs have ramifications in both the output as well as the labor markets. However, both these papers analyze market responses to EGS programs in the context of a dual economy characterized by a perfectly competitive rural labor market and urban unemployment à la Harris-Todaro ${ }^{3}$. While agrarian relations in rural India exhibit a variety of labor hiring arrangements - from active casual markets in both seasons, to tied-labor / implicit contracts to collective bargaining between laborers and landlords - the explicit and implicit objectives of the EGS and NREGS programs (highlighted above respectively) is to

\footnotetext{
${ }^{2}$ Some of the studies that revolve around the poverty alleviation aspect of EGS programs are: (a) the incentive argument of public works programs, specifically, the self-targeting and screening potential of these programs (Besley and Coate (1992)), (b) the use of means-tested and universal schemes in the alleviation of poverty (Besley (1990)), (c) schemes aiming at wide coverage at low wages and restricted coverage at higher wages (Ravallion (1991)), (d) transfer benefits from public works employment (Datt and Ravallion (1994)) and (e) the relative benefits of payments in cash or kind through these programs (Kaushik Basu (1981 \& 1990)).

${ }^{3}$ Following Harris and Todaro's (1970) classic formulation.
} 
target those laborers that are either involuntarily unemployed in the agricultural lean season or those that are desperate to escape the vicious cycle of poverty and debt. Thus, competitive rural labor market framework, given program objectives highlighted above, is hardly the suitable one for the purpose of analyzing agricultural labor market outcomes in the presence of either an NREGS or an EGS.

Two types of laborers, those either vulnerable to debt-bondage (through interlinked creditlabor contracts) or potential participants in tied-labor contracts (which generates involuntary unemployment in the lean season), fits best as the intended beneficiaries of the NREGS and EGS programs. Consider the institution of debt bondage first. Absent formal credit markets in rural areas, debt-bondage is a phenomenon where poor laborers borrow from richer landlords to finance subsistence consumption in the lean season with the pledge to repay the loan through labor services in the peak season. While these contracts are entered into voluntarily by poor laborers, usurious interest rates force them into a vicious cycle of debt. Frequently these laborers have no choice but to pledge the labor services of their children (in addition to their own labor services) in order to repay these loans. The phenomenon of debt-bondage for adult laborers has been studied by Genicot (2002), and for adult and child laborers by Basu and Chau (2003 and 2004). Basu and Chau (2003) explicitly consider the impact of an EGS program to alleviate debt-bondage, and show that while an EGS program may well be effective in targeting potential laborers from entering into such repressive credit-labor arrangements, a policy of subsidized credit may well be a more effective instrument in targeting potential and existing laborers vulnerable to debt-bondage.

The discussion above leaves the framework of two-tiered labor markets as the remaining one that is yet to be used for the evaluation of labor market outcomes in the presence of employment guarantee programs. To begin with, labor tying is usually observed where agricultural production exhibit seasonality as defined by low labor demand during the lean/slack season (dominated by activities like soil preparation, tilling and sowing) and usually high labor demand during the peak season (when the crop is harvested, threshed and stored/marketed). The presence of this production uncertainty, in turn, induces landlords to lock-in of a certain number of laborers at a pre-determined wage over both seasons to minimize production costs. Such locking-in of laborers still allows for the option to supplement tied-laborers with casual ones at the competitive wage in the peak season if actual peak season production does end up 
exceeding the anticipated level in the lean season (Bardhan 1979, 1983) ${ }^{4}$. A direct consequence of labor-tying (with an inactive casual labor market in the lean season) is involuntary unemployment - the explicit target group for the EGS and the implicit target of the NREGS to provide a hundred days of guaranteed employment.

Indeed, evidence suggests that tied-labor contracts (with accompanying involuntary unemployment) still exist in rural India. Although historically the Indian States of Bihar (including the State of Jharkhand) and Uttar Pradesh (including the State of Uttaranchal) had some of the highest incidence of attached or tied labor (Bardhan 1983), more recently tied labor is shown to be more pervasive in the Indian States of Andhra Pradesh, Madhya Pradesh, Rajasthan and Punjab. Using data from the Consumption Expenditure of Rural Labour Households survey of the Government of India (1999-2000), Deshingkar and Farrington (2006) show that in the State of Andhra Pradesh attached laborers are on yearly contracts and the demographic profile is almost exclusively male and between the ages of 10-70. The primary reason for a high percentage of attached or tied labor in Andhra Pradesh is due to a poor household's need for credit to pay off outstanding debt. Further, these attached labor contracts are entered into voluntarily and their incidence increases during the periods of draught which points to these contracts as an insurance mechanism. A similar pattern of attached labor is also found in Madhya Pradesh where feudal agrarian relations have led to the bonded labor contracts called Hali. These contracts entail an advance of a full-season's wages in lieu of a laborer working a certain number of hours for a particular landlord, and these wage advances are positively correlated with the prevailing agricultural wage. Attached labor contracts are also observed amongst the lower caste landless households in Rajasthan (Bhasin, 2004), as well as amongst migrant laborers in Punjab who are on annual contracts. Incidentally in Punjab, although the proportion of attached laborers to casual laborers is less than one, this proportion increases with the size of the land holdings (Singh et.al, 2007). Finally, village level studies by Motiram (2007) in the Telangana region of South India and by Rawal (2006) in rural Haryana also points to the existence of tied and attached laborers in these regions.

Unfortunately, comprehensive studies aimed at identifying the percentage of tied labor across

\footnotetext{
${ }^{4}$ Bardhan (1979) posits that labor tying arrangements of this nature stems from the landlords' motive to minimize recruitment costs in the peak season when labor demand is usually high. Bardhan (1983) provides an alternative hypothesis in that production uncertainty, coupled with the absence of insurance markets, enable landlords to offer contracts that ensure a certain income for risk-averse laborers. A third hypothesis revolves around the notion that laborers have an incentive to shirk, and hence contractual arrangements that guarantees a remuneration above a laborers' opportunity income may elicit loyalty (Eswaran and Kotwal, 1985).
} 
individual rural districts within the various States of India, and the corresponding district level implementation of the NREGS programs to ascertain the degree to which these programs are targeted towards tied laborers, do not yet exist. Nevertheless, it is important to map the concentration of NREGS programs across the Indian states to check whether a relatively higher number of these programs have, at the very least, been instituted in those States where the institution of tied labor has been reported by existing studies. In this regard, Chakraborty (2007) provides a comprehensive picture of the number of NREGS districts in each Indian State. The highest concentration of NREGS programs are in Bihar (23 districts), Uttaranchal (22 districts), Jharkhand (20 districts), Orissa (19 districts), Madhya Pradesh (18 districts), Andhra Pradesh (13 districts), Maharashtra (12 districts), West Bengal (10 districts), and Rajasthan, Kerala and Gujarat (6 districts each). Interestingly, Andhra Pradesh is also the State with one of the highest reported incidence of debt-bondage along with the States of Orissa, Uttar Pradesh and Karnataka for both agricultural and non-agricultural rural workers. Debt bondage, however, is observed to a lesser extent in Madhya Pradesh, Rajasthan and Punjab (Srivastava, 2005).

In light of the above, the main objective in this paper is to trace out the labor and output market responses to an EGS program instituted in the lean season to hire the rural unemployed and produce a public input. We consider a model of labor-tying that is a generalization of Bardhan's (1979) model in which monopsonistic landlords minimize recruitment costs by offering tied-labor contracts. In our model, risk-neutral, oligopsonistic landlords hire risk-averse, landless laborers to produce a single crop. The production of this crop is spread over two seasons, the lean and the peak with the peak season output subject to fluctuations in weather. Based on their expectation about peak season output, landlords choose the number of laborers to be hired as attached or permanent laborers at a fixed wage over the two seasons thereby giving rise to the institution of tied-labor contracts. If the peak season weather turns out to be better than expected, landlords supplement the need for additional labor through the hiring of casual laborers at the prevailing spot market wage.

The intuition behind the persistence of tied-labor contracts in the above setting follows from the fact that landlords, by accounting for the trade-off between the number of permanent hires and the peak season recruitment cost in their expected profit maximization calculus, offer permanent contracts at a wage that equates the value of the expected marginal revenue product of labor with the marginal cost of hiring over both seasons. Consequently, the permanent 
wage and the number of contracts offered is less than what obtains under a competitive setting leading to involuntary unemployment in the lean season ${ }^{5}$. In the absence of any alternative employment opportunities, laborers who fail to get permanent contracts rely solely on the competitive casual labor market to find agricultural employment in the peak season ${ }^{6}$. In the lean season, a productive EGS program fulfills the first of its three objectives by employing this group of otherwise unemployed laborers. Naturally, government hiring of unemployed laborers would affect labor allocations across both seasons directly through its effect on the wages and indirectly through its effect on peak season output.

A second important dimension of these EGS programs, hitherto neglected in the literature when accounting for market responses to public interventions, relates to their productive nature. It can be argued, inter alia, that productive assets or infrastructure created through an EGS program in the rural sector will have a direct impact on agricultural productivity as a public input. Indeed, if EGS were to undertake projects on irrigation or flood control measures in areas prone to droughts or flooding, it is only natural that output and labor hiring decisions takes into account the effect of these projects in mitigating such factors as weather fluctuations which customarily plague agricultural production. In fact, empirical studies by Binswanger, Khandker and Rosenzweig (1993) and Fan, Hazell and Thorat (2000) strongly suggest a positive relationship between government investment in infrastructure and agricultural output ${ }^{7}$.

\footnotetext{
${ }^{5}$ Tied labor contracts can also be generated in other settings, such as Eswaran and Kotwal's (1985) model where tied-contracts circumvent shirking by laborers. However, since the focus of our paper is about EGS programs that are the employer of the last resort, it is difficult to justify that landless laborers, with no alternative source of income, have an incentive to shirk if they find regular agricultural employment. Second, the choice of our framework is dictated by the observation that EGS programs guarantee jobs for only those unemployed in the agricultural sector and hence, unlike Mukherjee and Ray (1995), our framework precludes the existence of an active casual labor market in the lean season. It should also be noted, that the assumption regarding output uncertainty in this model is based on the realistic production environment in South Asia and is not necessary for the emergence \& persistence of tied-labor contracts. The assumption of oligopsony is sufficient for this purpose. In fact, in our model output uncertainty by itself will not lead to the prevalence of tied-labor contracts in an unfettered economy, unless additional assumptions are made regarding the production technology (see, for example, Bardhan 1983 and Basu, 2002).

${ }^{6}$ We assume that laborers in this economy have no other source of income except from that of either as an agricultural laborer or as an EGS employee. This assumption follows from the fact that EGS programs are directed primarily towards the rural landless as evidenced by the implementation of the Rural Landless Employment Guarantee Scheme under the seventh five-year plan (1985-1990) in India as well as a number of other programs such as the Jawahar Rozgar Yojana in 1989. Further, the extent of unemployment amongst landless agricultural laborers is significant in India (India Rural Development Report, 1999 and Mearns, 2000).

${ }^{7}$ Binswanger et.al points out that private agricultural investment and input use is more profitable the better the government infrastructure. Fan, Hazell and Thorat finds that investments in rural roads and agricultural research have the highest impact per rupee spent than any other government investment on agricultural productivity. Further evidence linking agricultural productivity with investment in rural infrastructure can be found in Thomas (1971) which suggests that yearly yields of paddy had increased as a result of the Rural Public Works program in Bangladesh. See also Narayana et.al (1988) for an empirical analysis of the costs and benefits of
} 
Additionally, Sathe (1991) reports that $91 \%$ of ex-EGS laborers find that rural employment guarantee schemes contributed to formal agricultural activity through work on protective irrigation to otherwise dry lands, and these assets created through EGS employment had led to positive developments in agricultural and rural non-agricultural activities.

In effect, our theoretical framework allows for an evaluation of a number of (sometimes) conflicting observations and empirical results on the impact of an EGS on agricultural wages, employment and output, as well as underscores the importance of the relative productivity of workers in the EGS program vis-à-vis their counterparts engaged in agricultural production in determining the success of these programs. As examples, Osmani and Chowdhury (1983) and Basu (1982) posit for Bangladesh and India respectively, that an EGS program exerts upward pressure on agricultural wages while Ravallion (1990) and Ahmad and Hossain (1985) show that an EGS displaces laborers from agricultural employment. We show that while the institution of an EGS program increases the permanent wage and displaces some permanent laborers into the pool of casual ones, the impact of an EGS program on the casual wage in the peak season may well be positive depending upon the relative productivity of the EGS laborers vis-à-vis their agricultural counterparts.

The final objective of our paper concerns the determination of the optimum wage to be paid in an EGS program taking into account its public good aspect. Although, the NREGS stipulates Rupees 60 as the daily renumeration for EGS workers, this pre-determined wage may well be inconsistent with one of the following three objectives: (i) screening the poor from the notso-poor insofar as who gets employed in the program, (ii) maximizing expected agricultural output and (iii) maximizing the welfare of the laborers in the economy. The first objective has received extensive treatment elsewhere. Our concern is therefore with the second and the third objectives. It should be noted that the objective of expected agricultural output maximization is of utmost importance not only because entitlement failures are the consequence of the loss of employment associated with bad harvests but also because assessments of harvest quality forms the basis of the annewari system of early warning in India ${ }^{8}$. Our findings indicate that the optimum wage consistent with expected agricultural output maximization almost always conflict with the one consistent with the objective of welfare maximization of the laborers. Thus, even though a pre-determined wage for EGS workers may accidentally fulfill one of the objectives, it is guaranteed to be in conflict with the other.

EGS programs in India.

${ }^{8}$ See Drèze (1990). 
The plan of the paper is as follows: section 2 develops the model and explains its workings. Section 3 analyzes market responses to EGS programs while section 4 focuses on the determination of the optimum wage. Section 5 provides a sketch of the impact of public works programs in alternative labor market settings. Finally, section 6 offers some concluding remarks.

\section{The Model}

\section{Landlords}

Consider an economy with $N$ identical, risk neutral, oligopsonistic landlords and a large number, $\mathcal{L}$, of homogeneous, risk averse landless laborers ${ }^{9}$. The total amount of land is fixed and equally divided amongst the landlords who maximize profit over an infinite horizon by hiring landless laborers to produce a single crop. During each time period, the production of this crop is spread over two seasons, the lean and the peak. Given expectations about weather conditions in the peak season, an individual landlord maximizes profit by choosing a fraction of the laborers to be hired as permanent or tied laborers at a fixed wage over the two seasons at the beginning of any time period. In the peak season, landlords hire casual laborers at the ongoing spot market wage to supplement permanent laborers ${ }^{10}$. Further, casual and permanent laborers perform the same task in the peak season.

Specifically, lean season output for the $i$ th landlord, $Q_{L}^{i}$, is given by,

$$
Q_{L}^{i}=\beta L_{P}^{i} ; \quad \beta>0
$$

where $\beta$ is a technology parameter affecting lean season output and denotes both the average and the marginal productivity of permanent laborers in the lean season.

The remaining laborers, i. e., the ones who fail to get permanent contracts in the lean season, are absorbed by a productive EGS program at a pre-determined wage, $\bar{w}$, for the creation and

\footnotetext{
${ }^{9}$ According to Sathe (1991), data collected through village level surveys in Maharashtra between 1987-1989 for 62 villages and 14345 households shows that half the job seekers in the EGS program were from the backward castes. In addition, $31 \%$ of the sample laborers were landless while $50 \%$ were marginal farmers, and $79 \%$ of the respondents alluded to the lack of alternative employment opportunities as the reason for choosing EGS work. In a recent study on the characteristics of job seekers in the NREGS programs in the State of Rajasthan, Jha, Bhattacharyya Gaiha and Shanker (2009) also show that members of the scheduled tribes and landless agricultural workers are the primary beneficiaries of these programs.

${ }^{10}$ Unlike Osmani (1991) and Mukherjee \& Ray (1992) laborers in this model do not have bargaining power in the casual labor market.
} 
maintenance of rural infrastructure ${ }^{11}$. We focus on EGS programs that are in effect only over the duration of the lean season based on (i) the observation that governments try to avoid competition with farmers over casual labor in the peak season when agricultural labor demand is usually high (Ravallion, 1990) and (ii) the guarantee of one hundred days of employment under the NREGS, which most likely will be accessed by the rural poor when the private labor market is inactive during the lean season ${ }^{12}$.

Let the shadow cost of public funds used for the EGS program be $\Pi>0$. In other words, each dollar spent by the government on direct job creation through an EGS program is either (a) raised through distortionary taxes and costs society $(1+\Pi)$ dollars $^{13}$ or (b) the opportunity cost of a dollar of foreign aid, not specifically tied to job creation through an EGS program is $(1+\Pi)$ dollars $^{14}$.

The production function for the EGS program is given by,

$$
Q_{G}=\alpha L_{G} ; \quad \alpha>0
$$

where $\alpha$ denotes both the marginal and average productivity of labor in this EGS program. By virtue of the employment guarantee scheme, the allocation of laborers across the EGS program and private production for the landlords in the lean season must satisfy:

$$
L_{G}+N L_{P}^{i}=\mathcal{L}
$$

where $N L_{P}^{i}$ is the total number of permanent contracts offered by the landlords.

Denote $A \in[\underline{A}, M]$ as the weather outcome in the peak season, where $\underline{A}$ and $M$ are respectively the worst and the best possible weather outcomes. Let $F(A)$ be the cumulative distribution function associated with the random variable $A$ with $f(A)=F^{\prime}(A)>0$ as the density function ${ }^{15}$.

\footnotetext{
${ }^{11}$ Following Basu (1990), we assume that the government hires, at a pre-determined wage, all laborers unable to find permanent contracts. Whether all workers seeking employment in EGS programs actually manage to find employment in Maharashtra has recently been studied by Ravallion, Datt and Chaudhuri (1993).

${ }^{12}$ Dev (1995, p 126) reports that EGS and agricultural employment are complementary in the sense that EGS employment is high in the lean season (April - July) and low in the peak season (October - January). For instance, in two villages within Maharashtra (Shirapur and Kanzara), the EGS and agricultural employment profiles for male agricultural laborers shows negative correlations of -0.68 and -0.33 respectively.

${ }^{13}$ We are in effect assuming that ideal lump-sum taxation is not available and higher the inefficiency of tax collection by the government the higher the value of $\Pi$.

${ }^{14}$ For instance, the Food-for-Work program in Bangladesh was financed by U.S aid under the PL-480 agreement, and is an example of foreign aid tied specifically to job creation programs (See Alamgir, 1983).

${ }^{15} \mathrm{~A} /$ denotes the first derivative of the variable in question.
} 
We shall assume that the expectation of $A\left(=\int_{\underline{A}}^{M} A f(A) d A\right)$, equals unity. Now, total output in the peak season depends on three inputs: (i) lean season output, $A \beta L_{P}^{i}$, comprised of the work done by permanent laborers, $\left(\beta L_{P}^{i}\right.$ denoting the amount of seeds planted etc.) along with the actual weather condition at the beginning of the peak season, ( $A$ denoting the amount of rainfall); (ii) the amount of work done in the peak season itself and (iii) the output of the EGS program, $\bar{Q}_{G}$, which plays the role of a public input affecting agricultural production in the peak season. Therefore, actual peak season output for an individual landlord is written as follows:

$$
Q_{H}^{i}=g\left(\bar{Q}_{G}\right) H\left(A \beta L_{P}^{i}, L_{a}^{i}\right) ; E(A)=1 ; H_{1}, H_{2}>0, H_{11}, H_{22}<0
$$

We shall assume that $H(\cdot, \cdot)$ is twice continuously differentiable, exhibits constant returns to scale and diminishing marginal productivity with respect to both inputs and $g(0)=1$ and $g^{\prime}>0, g^{\prime \prime}<0$. Note that $L_{a}^{i}=L_{P}^{i}+L_{C}^{i}=\frac{\mathcal{L}}{N}$ is the total amount of labor employed by an individual landlord in the peak season with $L_{C}^{i}$ as the number of casual laborers hired ${ }^{16}$.

Accordingly, a landlord's labor hiring decision follows a two-stage maximization problem. In the lean season, employment of permanent labor is determined. In the peak season, casual labor employment is determined given the prevailing spot wage, $w_{C}$, the amount of lean season output, $A \beta L_{P}^{i}$, and the amount of the EGS output, $\bar{Q}_{G}$.

With the price of the agricultural output exogenously given and normalized to unity, we shall begin with the peak season maximization problem of a typical landlord. Given $A \beta L_{P}^{i}$ and $\bar{Q}_{G}$, let $w_{C}^{i}$ be the wage offer of the $i$ th landlord and $l_{C}^{i}\left(w_{C}^{1}, \ldots, w_{C}^{j}, \ldots, w_{C}^{N}\right)$ be the corresponding casual labor supply to this landlord. Clearly, $w_{C}^{i}=w_{C}^{j}$ for all landlords since a lower wage offer by any landlord would result in a zero casual labor supply in return. Further, $w_{C}^{i}=w_{C}^{j}=$ $w_{C}$ is the competitive wage for the economy in the peak season due to the fact that under constant return to scale technologies, Bertrand competition by oligopsonistic landlords leads to a symmetric competitive outcome. Once $w_{C}$ is determined, the number of casual laborers employed by an individual landlord is given as a solution to

$$
\max _{L_{C}^{i}} g\left(\bar{Q}_{G}\right) H\left(A \beta L_{P}^{i}, L_{P}^{i}+L_{C}^{i}\right)-w_{C}^{i} L_{C}^{i} ; \quad \text { s.t } \quad L_{C}^{i} \leq l_{C}^{i}\left(w_{C}^{1}, \ldots \ldots, w_{C}^{N}\right)
$$

The equilibrium casual wage is thus given by

$$
w_{C}=g\left(\bar{Q}_{G}\right) H_{2}\left(A \beta L_{P}^{i}, L_{P}^{i}+L_{C}^{i}\right)
$$

\footnotetext{
${ }^{16}$ The total number of laborers in this economy, $N L_{P}^{i}+N L_{C}^{i}=N L_{a}^{i}=\mathcal{L}$, with $N L_{C}^{i}$ is the total number of casual laborers in the peak season.
} 
As a first step, we need to identify how the number of permanent contracts offered at the begining of the lean season affects the casual wage in the peak season. To this end, we need to pin down whether permanent and casual laborers are substitutes or complements of one another in the peak season. Thus, totally differentiating the above equation yields,

$$
\frac{\partial L_{C}^{i}}{\partial L_{P}^{i}}=-\frac{\left(-\alpha N g^{\prime} H_{2}+g A \beta H_{21}+g H_{22}\right)}{g H_{22}}
$$

Since $H(\cdot, \cdot)$ exhibits constant returns to scale, we utilize the fact that $L_{P}^{i} H_{21}+L_{C}^{i} H_{22}=0$, and noting that $-\frac{\alpha N g^{\prime} L_{P}^{i}}{g}=\epsilon_{L_{P}^{i}}^{g}<0$ is the elasticity of the EGS input with respect to permanent labor while $\frac{H_{2}}{H_{22} L_{C}^{i}}=\epsilon_{L_{C}^{i}}^{H_{2}}<0$ is the elasticity of peak season agricultural output with respect to casual labor we can rewrite the above equation as,

$$
\frac{\partial L_{C}^{i}}{\partial L_{P}^{i}}=-\frac{\epsilon_{L_{P}^{i}}^{g}}{\epsilon_{L_{C}^{i}}^{H_{2}}} \frac{L_{C}^{i}}{L_{P}^{i}}+A \beta \frac{L_{C}^{i}}{L_{P}^{i}}-1
$$

The right hand side of the above can be either positive or negative implying that permanent and casual laborers can be either complements or substitutes of one another in the peak season production process. As we show in Appendix A.1, if (i) $\epsilon_{L_{P}^{i}}^{g}$ is small, (ii) weather outcome $(A)$ is distinctly favorable, (iii) agricultural productivity $(\beta)$ in the lean season is large and (iv) the number of permanent laborers relative to the total labor force in the economy is small, then permanent and casual laborers complement one another. The economic intuition is simple: If the hiring of an additional permanent laborer has (i) a negligible adverse effect on the output of the EGS program and hence on the peak season agricultural output, (ii) revealed weather in the peak season is very good and (iii) if the marginal productivity of permanent laborers is very high (implying a large intermediate input for the peak season production function), then the hiring of an additional permanent laborer raises the productivity of all laborers in the peak leading to an increased need for casual laborers.

Thus, even though the casual labor market clears in the peak season at the prevailing market wage, the choice of permanent contracts will impinge upon the actual casual wage once weather conditions are revealed in the peak. In particular,

$$
w_{C}(A)=g\left(\bar{Q}_{G}\right) H_{2}\left(A \beta L_{p}^{i}, \frac{\mathcal{L}}{N}\right)
$$

where the right hand side of the above equation denotes the inverse demand function for casual labor. Assuming point expectation, i. e., a unique $w_{C}$ for every possible revelation of $A$, it is easy to see that the casual wage, $w_{C}$, is increasing in (i) the number of permanent contracts, 
$L_{P}^{i}$, (ii) the productivity of permanent laborers, $\beta$, (iii) the amoumt of EGS input generated in the lean season, $\bar{Q}_{G}$ and (iv) the revealed weather in the peak season, $A$.

The aggregate labor demand by all landlords across the peak and the lean season therefore satisfy

$$
(N-1)\left[L_{P}^{j}+L_{C}^{j}\left(w_{C}, L_{P}^{j}, A\right)\right]+L_{P}^{i}+L_{C}^{i}\left(w_{C}, L_{P}^{i}, A\right)=\mathcal{L},
$$

where $L_{P}^{j}$ and $L_{C}^{j}$ are, respectively, the demand for permanent and casual laborers for all landlords excluding the $i$ th one. Totally differentiating equation (6) we have

$$
\frac{d w_{C}}{d L_{P}^{i}}=-\frac{\left(1+\frac{\partial L_{C}^{i}}{\partial L_{P}^{i}}\right)}{(N-1) \frac{\partial L_{C}^{j}}{\partial w_{C}}+\frac{\partial L_{C}^{i}}{\partial w_{C}}}=-\frac{\left[-\frac{\epsilon_{P}^{g}}{\epsilon_{L_{C}^{i}}^{H_{2}}} \frac{L_{C}^{i}}{L_{P}^{i}}+A \beta \frac{L_{C}^{i}}{L_{P}^{i}}\right]}{(N-1) \frac{\partial L_{C}^{j}}{\partial w_{C}}+\frac{\partial L_{C}^{i}}{\partial w_{C}}}
$$

Since $\frac{\partial L_{C}^{j}}{\partial w_{C}}$ and $\frac{\partial L_{C}^{i}}{\partial w_{C}}$ are both negative, a low value of $\epsilon_{L_{P}^{i}}^{g}$ is sufficient to guarantee that the hiring of an additional permanent laborer raises casual labor demand thereby generating a positive relationship between the number of permanent hires in the lean season and the revealed casual wage in the peak season ${ }^{17}$.

\section{Laborers}

We start by focusing on the availability of permanent and casual labor jobs in the economy and the corresponding lifetime utilities of the laborers from these jobs. Our framework for the determination of the lifetime utilities of permanent and casual laborers follows closely that of Mukherjee and Ray (1995) and Basu (2002). Consider therefore a typical laborer in this economy at the beginning of the lean season. This laborer has the possibility of either (i) getting a permanent contract, available with probability $p$, and an associated wage $w_{P}$ paid at the end of each season or (ii) not get a permanent contract with probability $(1-p)$ and work in the EGS program for wage $\bar{w}$ in the lean season and work as a casual laborer for wage $w_{C}(A)$ in the peak ${ }^{18}$.

\footnotetext{
${ }^{17}$ We shall assume that $\frac{d^{2} w_{C}}{d\left(L_{P}^{i}\right)^{2}}<0$. Note also that by virtue of symmetry, all landlords hire the same number of permanent laborers.

${ }^{18}$ We do not consider the issue of access for laborers to the EGS program. In other words, all laborers willing to work for an EGS can do so without incurring any transaction costs. Basu, Chau and Kanbur (2009) consider the scenario where a government may use an EGS program as a rationing device by choice of location.
} 
Denoting $V_{*}$ as the lifetime utility of a laborer and $W_{*}$ as the lifetime utility of a laborer conditional on getting a permanent contract at the beginning of the lean season, we have:

$$
\begin{aligned}
V_{*} & =p W_{*}+(1-p)\left[U(\bar{w})+\rho \int_{\underline{A}}^{M} U\left(w_{C}\left(A, L_{P}^{i}, \beta\right)\right) f(A) d A+\rho^{2} V_{*}\right], \\
W_{*} & =(1+\rho) U\left(w_{P}\right)+\rho^{2}(1-q) W_{*}+\rho^{2} q V_{*},
\end{aligned}
$$

where $U(\cdot)$ is strictly concave and twice differentiable with $U^{\prime}>0$ and $U^{\prime \prime}<0 . \rho \in(0,1)$ is the rate at which laborers discount future utility and $q$ is an exogenously given quit rate from a permanent contract at the end of the "year" ${ }^{19}$. Solving simultaneously for $W_{*}$ and $V_{*}$ we get,

$$
V_{*}=\frac{1}{|\mathcal{Q}|}\left[p(1+\rho) U\left(w_{P}\right)+(1-p)\left(1-(1-q) \rho^{2}\right) \hat{U}\right]
$$

and

$$
W_{*}=\frac{1}{|\mathcal{Q}|}\left[\left(1-(1-p) \rho^{2}\right)(1+\rho) U\left(w_{P}\right)+\rho^{2} q(1-p) \hat{U}\right],
$$

where $|\mathcal{Q}|=\left(1-\rho^{2}\right)\left[\left(1-\rho^{2}\right)+\rho^{2}(q+p(1-q))\right]>0$ and $\hat{U}=U(\bar{w})+\int_{\underline{A}}^{M} U\left(w_{C}\right) f(A) d A$.

For a permanent contract to be acceptable to a laborer, it must be the case that $W_{*} \geq V_{*}$. Therefore, the acceptability constraint implies

$$
(1+\rho) U\left(w_{P}\right) \geq U(\bar{w})+\rho \int_{\underline{A}}^{M} U\left(w_{C}\left(A, L_{P}^{i}, \bar{Q}_{G}, \beta\right)\right) f(A) d A,
$$

otherwise tied labor contracts will never be accepted. However, note that the permanent wage in the peak season is lower than the expected casual wage since the permanent wage in the peak season is the certainty equivalent wage offered by landlords, and given that laborers are risk averse, must be less than the expected casual wage.

Consider now the following possibilities: (1) after having accepted a contract, a permanent laborer may quit and choose to remain unemployed in the lean season and (2) after having worked as a permanent laborer in the lean season, a permanent laborer may choose to join the casual labor pool in the peak season, particularly, when the revealed casual wage is high. The acceptability constraint guarantees that a permanent laborer will not choose option (1). For option (2) we again follow Mukherjee and Ray (1995) and Basu (2002) and assume that (i) in the case of such a deviation, the landlord terminates the contract without any pay for the peak season and the laborer is returned to the pool of casual laborers and (ii) a permanent laborer

\footnotetext{
${ }^{19} q$ is the exogenous probability of nonrenewal of a contract rather than a quit from an ongoing contract (See Mukherjee \& Ray (1995)).
} 
who reneges on a contract is scarred, i. e., the worker has a lower probability $\tilde{p}$ of obtaining a permanent contract the following "year". The extent to which $\tilde{p}$ differs from $p$ depends on the ease with which information regarding a reneger diffuses amongst landlords. Denoting the ease of information diffusion by $0<\mu<1$, a constant, we have $\tilde{p}=(1-\mu) p$. Even though landlords prefer a honest laborer to a reneger, a reneger's reputation is laundered once he finds a permanent contract. Thus, the lifetime utility of a reneger, $R_{*}$, at the beginning of the lean season is

$$
R_{*}=\tilde{p} W_{*}+(1-\tilde{p})\left[U(\bar{w})+\rho \int_{\underline{A}}^{M} U\left(w_{C}\right) f(A) d A+\rho^{2} R_{*}\right] .
$$

First note that $V_{*} \geq R_{*}$ and $W_{*} \geq R_{*}$. To ensure that a permanent laborer does not have the incentive to renege, landlords must offer a contract that is incentive-compatible. In other words, the incentive compatibility constraint must guarantee that the lifetime utility of a honest permanent worker $\left(W_{*}\right)$ is at least as high as that of a reneger, $\left(R_{*}\right)$. To this end, denote $w_{C}^{+}$ as the maximum possible casual wage in the beginning of any peak season consistent with the best possible weather outcome for a given number of permanent contracts. The discounted lifetime of a reneger in this scenario is $U\left(w_{C}^{+}\right)+\rho R_{*}$ while the discounted lifetime utility of a permanent laborer who chooses not to renege is $U\left(w_{P}\right)+\rho W_{*}$. The incentive-compatibility constraint must therefore guarantee that

$$
U\left(w_{P}\right)+\rho W_{*} \geq U\left(w_{C}^{+}\right)+\rho R_{*}
$$

Substituting for $W_{*}$ and $R_{*}$ in the above equation and rearranging yields ${ }^{20}$ :

$$
[1+\nu(1+\rho)] U\left(w_{P}\right) \geq \nu U(\bar{w})+\nu \rho \int_{\underline{A}}^{M} U\left(w_{C}\right) f(A) d A+U\left(w_{C}^{+}\right)
$$

where

$$
\nu=\frac{\rho(1-\tilde{p})\left(1-(1-p) \rho^{2}\right)}{\left(1-(1-\tilde{p}) \rho^{2}\right)\left[\left(1-\rho^{2}\right)+\rho^{2}(q+p(1-q))\right]}>0
$$

is the factor by which lifetime utility of a permanent worker is discounted. It follows that the discount factor $\nu$ is endogenously determined, depending on $L_{P}^{i}, p$ and $q$. In the sequel we shall assume that

\section{Assumption $1 \frac{\partial \nu}{\partial p}<0$.}

The reason behind assumption 1 is as follows. For a laborer with a permanent contract over two seasons, the discounted present value of lifetime utility of remaining a permanent laborer

\footnotetext{
${ }^{20}$ Appendix A.2 provides a formal derivation of the acceptability and incentive compatibility constraints.
} 
$\left(=\rho\left[W_{*}-V *\right]\right)$, is lower if the probability of being hired as a permanent laborer is high. Another way to interpret assumption 1 would be that the current period utility from reneging from a permanent contract $\left(=U\left(w_{C}^{+}\right)-U\left(w_{P}\right)\right)$, is higher if the probability of being hired as a permanent laborer is high at the beginning of any lean season ${ }^{21}$.

Before focusing on the determination of the terms of permanent contracts in the presence of an EGS, a few observations are in order. First, the incentive compatibility constraint accounts for all possible revelations of $w_{C}$ for a given number of permanent contracts. Second, it can be easily checked that if the incentive-compatibility binds then $W_{*}$ is strictly greater than $V_{*}$ or the lifetime utility of a permanent laborer is strictly greater than that of a casual one. Third, equation (10) ensures that the permanent wage is the lowest possible incentive compatible wage and therefore laborers will not be able to undercut the permanent wage, while full employment in the peak season ensures that laborers will not be willing to undercut the casual wage ${ }^{22}$. Fourth, $\int_{\underline{A}}^{M} w_{C} f(A) d A>w_{P}>\bar{w}$, i. e., the wage paid at the EGS program is the lowest in the economy. Finally, the probability of getting a permanent contract at the beginning of any time period or "year" is given simply as the ratio between the number of vacancies to the total pool of job seekers, i. e.,

$$
p=\frac{q N L_{P}^{i}}{\mathcal{L}-(1-q) N L_{P}^{i}} .
$$

Therefore, the proportion of tied labor in equilibrium is given by

$$
\frac{N L_{P}^{i}}{\mathcal{L}}=\frac{p}{q+p(1-q)}
$$

Noting that the incentive-compatibility constraint implies the acceptability constraint, the maximization problem pertaining to each individual landlord at the beginning of the lean season is:

$$
\max _{L_{P}^{i}, w_{P}^{i}} \frac{1}{(1-\rho)} \int_{\underline{A}}^{M}\left(\rho g\left(\bar{Q}_{G}\right) H\left(A \beta L_{P}^{i}, L_{P}^{i}+L_{C}^{i}\right)-(1+\rho) w_{P} L_{P}^{i}-\rho T C^{2}\right) f(A) d A
$$

subject to the following constraints,

$$
\begin{aligned}
(i) \quad L_{P}^{i} & \leq l_{P}^{i}\left(w_{P}^{1}, \ldots \ldots \ldots, w_{P}^{N}\right) \\
(i i) \quad[1+\nu(1+\rho)] U\left(w_{P}\right) & =\nu U(\bar{w})+\nu \rho \int_{\underline{A}}^{M} U\left(w_{C}\right) f(A) d A+U\left(w_{C}^{+}\right)
\end{aligned}
$$

\footnotetext{
${ }^{21}$ Appendix A.3 provides a proof of this result.

${ }^{22}$ The interested reader is referred to Mukherjee and Ray (1995) for a detailed discussion of the incentivecompatibility problem that arises when laborers are averse to income fluctuations. As a comparison, Mukherjee and Ray develop their model of labor-tying within a framework characterized by perfectly competitive landlords, absence of uncertainty and an active casual labor market in the lean season.
} 
where the peak season casual wage cost is given by

$$
T C^{2}=w_{C} L_{C}^{i}=g\left(\overline{Q_{G}}\right) H_{2}\left(A \beta L_{P}^{i}, \frac{\mathcal{L}}{N}\right)\left[\frac{\mathcal{L}}{N}-L_{P}^{i}\right]
$$

The first order conditions with respect to $L_{P}^{i}, w_{P}$ and the Lagrange multiplier $\lambda$ are:

$$
\begin{aligned}
\frac{\rho}{(1-\rho)} \int_{\underline{A}}^{M}\left[A \beta H_{1}-\alpha N g^{\prime} H+w_{C}-\frac{d w_{C}}{d L_{P}^{i}}\left(\frac{\mathcal{L}}{N}-L_{P}^{i}\right)\right] f(A) d A-\frac{(1+\rho)}{(1-\rho)} w_{P} & =\lambda \Omega \\
\frac{(1+\rho) L_{P}^{i}}{(1-\rho)[1+\nu(1+\rho)] U^{\prime}\left(w_{P}\right)} & =\lambda \\
{[1+\nu(1+\rho)] U\left(w_{P}\right)-\nu U(\bar{w})-\nu \rho \int_{\underline{A}}^{M} U\left(w_{C}\right) f(A) d A-U\left(w_{C}^{+}\right) } & =0
\end{aligned}
$$

where

$$
\Omega=\nu \rho \int_{\underline{A}}^{M} U^{\prime}\left(w_{C}\right) \frac{d w_{C}}{d L_{P}^{i}} f(A) d A-\frac{\partial \nu}{\partial L_{P}^{i}}\left[W_{*}-V_{*}\right]+U^{\prime}\left(w_{C}^{+}\right) \frac{d w_{C}^{+}}{d L_{P}^{i}}
$$

The formalization of our model is now complete. We have 9 unknowns $w_{P}, w_{C}, L_{P}^{i}, L_{C}^{i}, \lambda, Q_{G}$, $Q_{L}^{i}, Q_{H}^{i}$ and $p$ which can be solved using equations (1) - (6) and equations (11) - (13). First, equations (12) and (13) can be solved simultaneously to obtain the values for $L_{P}^{i}$ and $w_{P}$ after substituting for $\lambda$ into equation (12) from (13). Once $L_{P}^{i}$ is known, equation (1) determines $Q_{L}^{i}$, equation (2) determines $L_{G}$ and therefore equation (3) determines $Q_{G}$ while equation (11) determines $p$. Given $L_{P}^{i}, w_{P}$ and $p, \lambda$ is determined from equation (13). With $L_{P}^{i}$ given, $w_{C}$ as a function of $A$ is determined from equation (5), and hence $L_{C}^{i}$ is determined from equation (6). Finally, given $L_{C}^{i}$ and $L_{P}^{i}$, equation (4) can be used to determine $Q_{H}^{i}$ as a function of $A$. We are now in a position to discuss the labor market response to a government intervention through an EGS program.

\section{Labor Market Response to an EGS Program}

In this section we analyze the labor market response to a (i) change in the wage paid at the government EGS program (an increase in $\bar{w}$ ), (ii) productivity increase of workers in the EGS program (an increase in $\alpha$ ) and (iii) productivity increase (technological improvement) in the agricultural sector that affects lean season output (an increase in $\beta$ ). We begin with the following proposition ${ }^{23}$ :

Proposition 1 An increase in $\bar{w}$ leads to an increase in $w_{P}$, a decrease in $L_{P}$, a decrease in $Q_{L}$ and an increase in $Q_{G}$. The casual wage in the peak season $w_{C}$ and expected agricultural

\footnotetext{
${ }^{23}$ Proofs of all propositions in sections 3 are presented in Appendix B.1. Further, in the notations that follow, $L_{P}=N L_{P}^{i}, Q_{L}=N Q_{L}^{i}$ and $L_{C}^{d}=N L_{C}^{i}$ etc., denoting aggregate levels of the variables.
} 
output, $\mathcal{E} Q_{H}$, increases (decreases) if and only if the elasticity of the EGS input in the peak season production function with respect to permanent labor $\left(\left|\epsilon_{L_{P}^{i}}^{g}\right|\right)$, is greater than the elasticity of expected agricultural output with respect to permanent labor $\left(\epsilon_{L_{P}^{i}}^{\mathcal{E} Q_{P}}\right)$.

The intuition behind proposition 1 is as follows: ceteris paribus, an increase in the wage paid in the EGS program implies, via the incentive compatibility constraint, an increase in the permanent wage. This in turn implies a decline in the number of permanent contracts offered and hence an increase in the pool of laborers seeking casual employment in the peak season. However, the impact of an EGS wage increase on the peak season casual wage as well as on expected agricultural output is determined by two opposing forces at play. On one hand, the displacement of permanent laborers deepens the casual labor pool and would tend to have a negative impact on both the casual wage as well as expected agricultural output due to loss in lean season input engendered through the displacement of permanent labor into the casual pool. This is the displacement effect of an EGS wage increase. On the other hand, a productive EGS has a positive impact on casual labor demand and expected agricultural output in the peak season for every value of $A$ through the increase in the EGS input in the lean season. This is the productivity effect. Recalling that $w_{C}=g\left(\bar{Q}_{G}\right) H_{2}\left(A \beta L_{P}^{i}, \frac{\mathcal{L}}{N}\right)$ from equation (5), if the elasticity of the EGS input with respect to permanent labor (in absolute value) is greater than the elasticity of expected agricultural output with respect to permanent labor, the loss in expected agricultural output (due a decline in lean season output when the number of contracts fall in response to an increase in $\bar{w}$ ) is dominated by the increase of the EGS input into the peak season production function due to an increase in the number of laborers seeking EGS employment in the lean season. Labor demand in the peak season and casual wages along with expected agricultural output therefore increases in response to an EGS wage increase.

Proposition 1 is consistent with studies which indicates that implementation of EGS programs (any positive wage offered for alternative employment) exert upward pressure on average agricultural wages (Osmani \& Chowdhury, 1983), and displaces workers from agricultural employment (Ravallion, 1990 and Ahmad \& Hossain, 1985). More specific to proposition 1, there are empirical studies subsequent to the May 1988 EGS wage increase in Maharashtra that sheds light on the forces that might be at play in a two-tiered agricultural labor market. The question of whether this EGS wage hike had an impact on formal agricultural wages and employment is studied by Dev (1995). According to Dev (1995) average EGS wage in 1976/77 was Rs.2.81 and much less than the average agricultural wage of Rs.13.20. After the EGS wage increase in 1989/90 the average EGS wage of Rs.15.53 exceeded the average agricultural wage of Rs.11.80 
in Maharashtra. Sathe (1991) and Dev (1995) posit that the EGS wage increase in 1988 might have led to an upward pressure on agricultural wages while Sathe (1991) concludes that agricultural employment increased after the post-EGS wage hike although this increase might have been generated due to increased agricultural productivity as a result of the assets created through EGS work. In the event that the agricultural sector indeed exhibited a two-tiered labor market, an increase in the EGS wage would increase the permanent wage and decrease number of permanent contracts. However, focusing on just the competitive casual labor market, the ensuing increase in the pool of casual laborers would depress the casual wage as a first round effect but the subsequent increase in agricultural productivity due to the impact of EGS work could well dominate this first round effect to show an overall increase in the casual wage in the peak season ${ }^{24}$.

Nevertheless, it bears emphasis that empirical studies conducted after the EGS wage increase in Maharashtra in 1988 implicitly assume a competitive agricultural labor market even though a variety of labor hiring arrangements are likely to be prevalent within the State of Maharashtra. As such, the empirical results delineated above after the 1988 EGS wage increase should not be interpreted as either a reinforcement or a rejection of our theoretical findings based on a two-tiered labor market structure. However, our proposition above with regards to the impact of an EGS wage increase on just the peak season competitive agricultural wage and employment can well be observationally consistent with the above empirical studies. It is worth noting here that even in the absence of or a minimal impact on agricultural productivity in the peak season through EGS work done in the lean season, demand for casual labor may well increase due to a positive weather shock - a variable ignored by prior empirical studies / surveys that aimed at estimating the impact of an EGS wage on agricultural wages and employment.

We next turn to the question of how productivity changes in the EGS program, and in the agricultural sector impact labor market responses. First, consider an increase in the productivity of laborers in the EGS program. As a starting point, suppose that $\epsilon_{\alpha}^{Q_{G}}>0$, or the output

\footnotetext{
${ }^{24}$ However, Datt and Ravallion (1994) found that the average monthly expenditure on EGS programs fell after the wage hike and employment in these programs fell by a third pointing to employment rationing in the EGS programs after the wage increase and that the increase in the EGS wage did not have an impact on agricultural wages. The issue of rationing in EGS employment is analyzed theoretically by Basu, Chau and Kanbur (2009) where the government jointly maximizes the EGS wage and access to EGS employment given an aggregate employment target. Basu, Chau and Kanbur show that the credibility of such an employment target is endogenously determined by a host of factors (distributional concern of the planner and private sector productivity, amongst others). An explicit model of employment rationing in EGS programs either through access or changes in budgetary outlay is beyond the scope of this paper.
} 
elasticity of the EGS program is positive with respect to a technological change. In this case, seasonal labor markets and agricultural output responds according to,

Proposition 2 An increase in $\alpha$ increases $w_{P}, L_{P}, Q_{L}$, and increases $w_{C}$ if the elasticity of the marginal product of EGS input in peak season agricultural production with respect to $Q_{G}$ $\left(\epsilon_{Q_{G}}^{g^{\prime}}\right)$ is close to negative unity. If in addition, the elasticity of expected agricultural output with respect to permanent labor $\epsilon_{L_{P}^{i}}^{\mathcal{E} Q_{P}}$ is greater than the elasticity of the EGS input in the peak season production function with respect to permanent labor $\left|\epsilon_{L_{P}^{i}}^{g}\right|$, then $\mathcal{E} Q_{H}$ increases.

Proposition 2 indicates that a yield-increasing improvement in technology originating from the government project increases the number of permanent contracts if $\epsilon_{Q_{G}}^{g^{\prime}} \rightarrow-1$. The reason being that if landlords hire less permanent workers in the lean season under the above sufficient condition, the negative impact of the lean season agricultural output dominates the positive impact of an increase in the productivity of the EGS output on agricultural production in the peak season. This results in a decline in expected agricultural output. Therefore, the number of permanent contracts must rise in response to productivity increases in the EGS program to prevent a decline in expected agricultural output. The increase in the number of permanent contracts increases lean season agricultural output, and tightens the pool of casual laborers which causes an increase in the casual wage. Furthermore, the increase in the casual wage entails an increase in the permanent wage via the incentive compatibility constraint.

Consider now the impact of a productivity increase affecting lean season agricultural production on labor hiring decisions and expected agricultural output. Suppose that at the beginning of the lean season there is, say, an increase in the usage of inputs such as fertilizers and/or increased mechanization that has a positive effect on the productivity of permanent workers. Then ${ }^{25}$

Proposition 3 An increase in $\beta$ increases $w_{P}, L_{P}$, decreases $Q_{G}$ and increases $w_{C}$ if (i) $\epsilon_{L_{P}^{i}}^{g}>-1$ and (ii) the elasticity of the marginal product of lean season output (in the peak season) with respect to permanent labor $\left(\epsilon_{L_{P}^{i}}^{H_{1}}\right)$ is close to zero. If in addition, the elasticity of expected agricultural output with respect to permanent labor $\epsilon_{L_{P}^{i}}^{\mathcal{E} Q_{P}}$ is greater than the elasticity of the EGS input in the peak season production function with respect to permanent labor $\left|\epsilon_{L_{P}^{i}}^{g}\right|$, then $\mathcal{E} Q_{H}$ increases.

Suppose that $\epsilon_{L_{P}^{i}}^{H_{1}} \rightarrow 0$ and $\epsilon_{L_{P}^{i}}^{\mathcal{E} Q_{P}}>\left|\epsilon_{L_{P}^{i}}^{g}\right|$. Now if $\epsilon_{L_{P}^{i}}^{g}$ is sufficiently large, then an increase in $\beta$ leads to an increase in expected agricultural output even when the number of permanent

\footnotetext{
${ }^{25}$ We shall assume for simplicity that $\epsilon_{\beta}^{Q_{L}}$, the elasticity of lean period output with respect to technological change affecting its output is positive.
} 
contracts fall. This happens because the increase in the EGS input into the peak season agricultural production due to a larger number of laborers seeking EGS employment is more than sufficient to outweigh the fall in peak season agricultural production caused by a decline in lean season agricultural output due to a fewer number of permanent laborers. A fewer number of permanent laborers in turn increases the pool of casual laborers and depresses the casual wage for every value of $A$. For the incentive-compatibility constraint to hold in equilibrium, a decline in the casual wage implies a fall in the permanent wage as well. On the other hand, for $\epsilon_{L_{P}^{i}}^{g}>-1$, the number of permanent laborers hired increases, and the subsequent increase in the lean season output overweighs the fall in the EGS input leading to an increase in expected agricultural output. In the event where $\epsilon_{L_{P}^{i}}^{g}>-1$, proposition 3 is consistent with the empirical findings of Bardhan (1983) which demonstrates a positive correlation between land productivity and the number of permanent contracts.

The labor and output market responses to changes in the above three parameters has interesting implications for policy formulations. Conditional on the way in which labor demand in the two seasons vary in accordance with changes in the policy instruments, a natural question arises as to whether by directly improving the income of the rural unemployed or indirectly through (a) raising the productivity of EGS programs and/or (b) inducing technological change in the agricultural sector, will the interests of the poor be best served. We conjecture that an indirect mechanism in the form of inducing technological improvement in the agricultural sector increases the income of the laborers relative to a direct policy such as raising the wage paid in the EGS program provided, (i) $\epsilon_{L_{P}^{i}}^{H_{1}} \rightarrow 0$, (ii) $\epsilon_{L_{P}^{i}}^{g}>-1$ and (iii) $\epsilon_{Q_{G}}^{g^{\prime}} \rightarrow-1$. If there remains an element of uncertainty as to whether induced technological improvement will in fact take place ${ }^{26}$, raising the productivity of laborers in the EGS program through an increase in $\alpha$ would have the same desired effect. In fact, productivity increases in the EGS program is a superior policy vis-a-vis wage increases in the program both in terms of improving the employment opportunities of the laborers as well as through its ability to increase agricultural production. As propositions 1 and 2 underscore, indirect intervention through an improvement in the productivity of a EGS program has a positive impact on agricultural production as compared to a direct increase in the EGS wage if the elasticity of expected agricultural output with respect to permanent labor $\left(\epsilon_{L_{P}^{i}}^{\mathcal{E} Q_{P}}\right)$ is greater than the elasticity of the EGS input in the

\footnotetext{
${ }^{26}$ It might very well be the case that landlords voluntarily refuse to undertake technological change affecting lean season output since such an increase corresponds to a higher wage bill and might end up reducing the profit margin. For instance, Braverman \& Stiglitz (1986) analyzes whether such technological innovations are undertaken by landlords in the context of share tenancy contracts.
} 
peak season production function with respect to permanent labor $\left(\left|\epsilon_{L_{P}^{i}}^{g}\right|\right)$. Indeed, as we shall point out in the next section, even when funds for an EGS program are unlimited, indirect intervention might prove to be a better option.

\section{Determination of the Optimum Wage}

Existing theoretical models due to Ravallion (1990) and Khan (1993) analyze market responses to EGS programs by assuming that laborers working in an EGS project are paid the ongoing wage in the agricultural sector. Basu (1990), on the other hand, has shown that wages paid at the EGS in Maharashtra and the RPW program in Bangladesh has been too low and ought to be raised to the point where the minimum compensation to an EGS employee equates the potential employment schedule ${ }^{27}$ with the labor supply schedule for the EGS program. A minimum wage determined in this fashion, while guaranteeing self-selection amongst the poor and not-so-poor in so far as the question of who should be employed in an EGS program is concerned, may be inadequate to achieve the objective of, say, agricultural output maximization. Clearly then, the nature of such an appropriate wage depends on the objective which the government wishes to pursue.

As stated in the Introduction, an important objective of EGS programs that is particularly relevant in the context of poverty alleviation is to maximize agricultural production that ensures the availability of food and reduces the dependence on imports. Thus, a wage $\bar{w}_{o}$, which achieves the goal of expected agricultural output maximization net of the shadow cost of public funds may serve as one criterion for an optimal compensation for an EGS employee. Accordingly consider,

$$
\max _{\bar{w}_{o}} \rho \int_{\underline{A}}^{M} N Q_{P}^{i} g\left(Q_{G}\right) f(A) d A-(1+\Pi) \bar{w} N L_{C}^{i},
$$

where $N Q_{P}^{i}=N H\left(A \beta L_{P}^{i}, L_{P}^{i}+L_{C}^{i}\right)$ is the total private output of the economy; $N L_{C}^{i}=$ $\mathcal{L}-N L_{P}^{i}=L_{G}$ and $g\left(Q_{G}\right)=g\left(\alpha\left(\mathcal{L}-N L_{P}^{i}\right)\right)$ is the EGS input in agricultural production. Provided that the second order conditions are fulfilled, the first order condition corresponding to the foregoing maximization problem follows,

$$
\rho \int_{\underline{A}}^{M} N Q_{P}^{i} g\left(Q_{G}\right) f(A) d A\left(\epsilon_{L_{P}^{i}}^{\mathcal{E} Q_{P}}+\epsilon_{L_{P}^{i}}^{g}\right) \frac{d L_{P}^{i}}{d \bar{w}} \frac{\bar{w}}{L_{P}^{i}}-(1+\Pi) \bar{w} N L_{C}^{i}\left(1+\epsilon_{\bar{w}}^{L_{C}^{i}}\right)=0
$$

\footnotetext{
${ }^{27}$ If the total amount of funds available for relief work is $X$, then given a wage $G$ the maximum number of laborers that can be employed is simply $X / G$. The schedule that traces out this relationship for different values of $G$ is the potential employment schedule.
} 
Thus the optimal wage $\bar{w}_{o}$ must be set at a level such that,

$$
\frac{\left(\epsilon_{L_{P}^{i}}^{\mathcal{E} Q_{P}}+\epsilon_{L_{P}^{i}}^{g}\right)}{\left(1+\epsilon_{\bar{w}}^{L_{C}^{i}}\right)} \epsilon_{\bar{w}}^{L_{P}^{i}}=\frac{(1+\Pi) \bar{w} N L_{C}^{i}}{\rho \int_{\underline{A}}^{M} N Q_{P}^{i} g\left(Q_{G}\right) f(A) d A} \equiv \delta^{R},
$$

where $\delta^{R}>0$ if and only if $\bar{w}>0$ and equals the share of EGS outlays per unit of expected agricultural output. Note also that,

- $\epsilon_{L_{P}^{i}}^{\mathcal{E} Q_{P}}$ is the elasticity of the expected agricultural output with respect to permanent labor and is positive,

- $\epsilon_{L_{P}^{i}}^{g}$ is the elasticity of the EGS output with respect to permanent labor and is negative (the higher the number of permanent laborers hired, the lower the number of laborers hired in the EGS program and hence lower the amount of the EGS output),

- $\epsilon_{\bar{w}}^{L_{C}^{i}}$ is the elasticity of casual labor with respect to the EGS wage and is positive (the higher the EGS wage the lower the number of permanent laborers hired by virtue of the incentive-compatibility constraint, resulting in a larger number of casual laborers seeking employment in the peak season),

- $\epsilon_{\bar{w}}^{L_{P}^{i}}$ is the elasticity of permanent hires with respect to the EGS wage and is negative.

Two comments are in order. First, equation (15) captures the fact that an EGS program should pay a positive wage if and only if $\left(\epsilon_{L_{P}^{i}}^{\mathcal{E} Q_{P}}+\epsilon_{L_{P}^{i}}^{g}\right)$ is negative. Second, equation (15) also captures the fact that if the elasticity of expected agricultural output with respect to permanent labor is low then, as indicated by our results in proposition 1, the wage compensation to EGS laborers should be relatively high so as to attract a larger number of laborers to the EGS program and vice versa when the expected elasticity of output with respect to permanent labor is high. It can easily be checked that the optimal level of productivity for an EGS and for the agricultural sector $(\alpha$ and $\beta$ ) respectively that maximizes expected output is given by same condition as in equation (15).

A second, yet perhaps more direct objective to follow is one which maximizes the ex-ante expected lifetime welfare of a new laborer joining the labor market in the economy. Such a laborer could either become a permanent laborer with probability $p$ or a casual laborer with probability $(1-p)$. The expected lifetime utility of such a laborer is given by

$$
V_{*}=\frac{1}{|\mathcal{Q}|}\left[p(1+\rho) U\left(w_{P}\right)+(1-p)\left(1-(1-q) \rho^{2}\right) \hat{U}\right]
$$


where $\hat{U}=U(\bar{w})+\rho \int_{\underline{A}}^{M} U\left(w_{C}\right) f(A) d A$ and $|\mathcal{Q}|=\left(1-\rho^{2}\right)\left[\left(1-\rho^{2}\right)+\rho^{2}(q+p(1-q))\right]>0$.

The optimum wage $\bar{w}_{v}$ then can be obtained as a solution to the following condition ${ }^{28}$,

$$
\begin{gathered}
\left.\left(\frac{\epsilon_{w_{P}}^{u} \epsilon_{\bar{w}}^{w_{P}}}{\epsilon_{L_{P}}^{p} \epsilon_{\bar{w}}^{L_{P}}}\right)+1\right]+(1-p)\left(1-(1-q) \rho^{2}\right)\left[U\left(\bar{w}_{v}\right) \epsilon_{\bar{w}}^{u}+\rho \int_{\underline{A}}^{M} U\left(w_{C}\right) f(A) d A\left(\frac{\epsilon_{w_{C}}^{u} \epsilon_{L_{P}}^{w_{C}} \epsilon_{\bar{w}}^{L_{P}}}{\epsilon_{L_{P}}^{p} \epsilon_{\bar{w}}^{L_{P}}}\right)\right. \\
=\frac{\left[\rho^{2}\left(1-\rho^{2}\right)(1-q) p\right] V_{*}}{p(1+\rho) U\left(w_{P}\right)}
\end{gathered}
$$

where

- $\epsilon_{j}^{u}>0 ; j=w_{P}, w_{C}$ and $\bar{w}$ is the elasticity of utility with respect to the permanent, casual and the EGS wage respectively,

- $\epsilon_{\bar{w}}^{w_{P}}$ is the elasticity of the permanent wage with respect to the EGS wage and is positive since an increase in the wage paid at the EGS program engenders an increase in the permanent wage to preserve the incentive compatibility constraint,

- $\epsilon_{L_{P}}^{p}$ is the elasticity of the probability of finding employment as a permanent laborer with respect to the number of permanent laborers and is positive. Note that the probability of finding employment as a permanent laborer is denoted simply as the ratio of the number of vacancies to the number of laborers seeking employment as a permanent laborer. Therefore, an increase in the number of permanent hires, given a fixed quit rate, increases the number of vacancies while simultaneously reducing the number of job seekers which, in turn, increases the probability of finding employment as a permanent laborer.

- $\epsilon_{\bar{w}}^{L_{P}}$ is the elasticity of permanent hires with respect to the EGS wage and is negative since an increase in the EGS wage leads to an increase in the permanent wage and hence a reduction in the number of permanent laborers hired,

- $\epsilon_{L_{P}}^{w_{C}}$ is the elasticity of the casual wage with respect to the number of permanent laborers and is positive since an increase in the number or permanent hires tightens the casual labor market and leads to an increase in the market clearing casual wage.

Equation (16) captures the fact that the optimum wage consistent with the maximization of the ex-ante expected lifetime welfare of a laborer must account for two distinct labor market responses on the ex-post expected lifetime welfare of a laborer. First, those laborers who find

\footnotetext{
${ }^{28}$ Please refer to the Appendix II.B for a detailed derivation of equation (16).
} 
employment as permanent ones are better-off since the permanent wage increases in response to an increase in the EGS wage. However, the probability of finding employment as a permanent laborer falls since the decline in the number of permanent hires subsequent to an increase in the permanent wage implies fewer vacancies in equilibrium. Second, the ensuing increase in the number of casual laborers implies a lower market clearing casual wage in the peak season which, depending upon the elasticity of the casual wage with respect to permanent labor and the elasticities of the utility function with respect to the casual and the EGS wage, may actually make a casual laborer worse-off. For instance, if both the elasticity of the probability of employment as a permanent laborer with respect to the number of permanent hires and the elasticity of the number of permanent hires with respect to the EGS wage are large, then there is a large displacement of permanent laborers caused by an increase in the EGS wage. This displacement effect coupled with a high elasticity of the casual wage with respect to the number of permanent hires would tend make a casual laborer worse-off. In this case $\bar{w}_{v}$ should be kept very low in order to ensure that the number of permanent laborers displaced is very small.

As a third objective, the government might want to maximize the expected welfare of casual workers (the poorest in this economy) at any given time period. Such an optimum government wage, $\bar{w}_{u}$, consistent with the objective of expected welfare maximization of casual workers can be deduced as a solution to

$$
U\left(\bar{w}_{u}\right) \epsilon_{\bar{w}}^{u}=-\rho \int_{\underline{A}}^{M} U\left(w_{C}\right) f(A) d A\left(\epsilon_{w_{C}}^{u} \epsilon_{\bar{w}}^{w_{C}}\right) .
$$

That $\bar{w}_{o}, \bar{w}_{v}$ and $\bar{w}_{u}$ may not be consistent with the objectives of maximizing expected agricultural output and the ex-ante expected lifetime welfare of a laborer (either a potentially new entrant to the labor force or a casual one) should be clear from equations (15), (16) and (17). To see this, consider for instance the extreme case where the EGS program is unproductive, i. e., the government hires the rural unemployed in the lean season to build roads and bridges which get washed away. In terms of our model, peak season output $Q_{H}$ is then independent of $\bar{Q}_{G}$. It is easy to see that the optimum wage paid for the EGS program consistent with the objective of maximizing expected output, in this case, should satisfy the condition $\frac{\epsilon_{L_{P}^{i}}^{\mathcal{E Q}}}{\left(1+\epsilon_{\bar{w}}^{L^{i}}\right)} \epsilon_{\bar{w}}^{L_{P}^{i}}=\delta^{R}$. Since $\epsilon_{\bar{w}}^{L_{P}^{i}}$ is negative, the optimum wage should be zero. This is what one should expect since an unproductive EGS program only serves to displace laborers away from agriculture and hence agricultural output must fall as the EGS program competes with landlords for laborers. On the other hand, a zero wage for instance, which is perfectly justifiable in the event where the 
EGS program should not interfere with agricultural production decisions, cannot be one which simultaneously maximizes the welfare of a laborer in this economy.

A final criteria that a government might wish to pursue through the institution of EGS programs is to explicitly address poverty alleviation - specially for the casual laborers whose annual income is subject to considerable income variability in the presence of production uncertainty. Consider therefore the Foster, Greer and Thorbecke (1984) $P_{\alpha}$ index of poverty for the casual laborers in the economy (see also Fields and Kanbur (2007)).

$$
P_{\alpha}=\frac{L_{C}}{\mathcal{L}}\left\{\frac{z-\left(\bar{w}+w_{C}\right)}{z}\right\}^{\alpha}
$$

where $z$ is the poverty line, $\left(\bar{w}+w_{C}\right)$ is the annual income of the casual laborers from EGS and peak season employment combined and $\frac{L_{C}}{\mathcal{L}}$ is the fraction of the casual laborers in the economy. Differentiating the above equation with respect to the EGS wage $\bar{w}$ and simplifying we have

$$
\frac{d P_{\alpha}}{d \bar{w}}=\frac{P_{\alpha} L_{C}}{\bar{w} \mathcal{L}}\left[\epsilon_{\bar{w}}^{L_{C}}-\frac{\alpha \bar{w}}{z-\left(\bar{w}+w_{C}\right)}\left(1+\frac{d w_{c}}{d \bar{w}}\right)\right]>(<) 0
$$

In general the impact of an EGS wage increase on the poverty index of casual laborers is indeterminate since the elasticity of casual labor supply with respect to the EGS wage, $\epsilon_{\bar{w}}^{L_{C}}$, is

negative while $\frac{d w_{c}}{d \bar{w}}$ can be either positive or negative. However, if the if the elasticity of the EGS input in the peak season production function with respect to permanent labor $\left(\left|\epsilon_{L_{P}^{i}}^{g}\right|\right)$, is greater than the elasticity of expected agricultural output with respect to permanent labor $\left(\epsilon_{L_{P}^{i}}^{\mathcal{E} Q_{P}}\right)$ then casual wages increase with an increase in the EGS wage, and the poverty index for casual laborers unambiguously falls. Once again, the relative productivity of EGS laborers vis-à-vis their agricultural counterparts play a crucial role in determining how effective an EGS program is in alleviating poverty.

\section{$5 \quad$ NREGS / EGS in Alternative Labor Market Settings}

Given that a variety of labor hiring arrangements exist in rural India, we sketch the the potential impact of an EGS on agricultural employment and wages under some alternative labor hiring mechanisms.

Collective Bargaining: In a recent paper, Dasgupta (2009) models an economy with two labor unions (an advanced and a backward class) simultaneously contesting a legislated minimum wage against a single employer and higher employment shares against each other. Such 
a model, at least within India, is more applicable to Indian States like Kerala where labor unions are strong and collective bargaining laws are enforced more regularly as compared to Indian States like Bihar and Orissa. In fact, an empirical study undertaken by Shanmugam and Vijayalakshmy (2005) in Palakkad district in Kerala and Nagapattinam district of Tamil Nadu shows that education and income from non-agricultural activities were the most significant factors influencing the labor union participation by the laborers. Nevertheless, the key idea in Dasgupta (2009) is that a landlord hires workers from both the advanced and backward caste groups, and the maximum per-worker wage that a landlord can pay, $\bar{W}$, is greater than the reservation wage of the both the advanced $\left(w_{A}\right)$ and backward $\left(w_{B}\right)$ caste workers (or $\left.\bar{W}>w_{A}>w_{B}\right)$. Consider now the case of a government mandated minimum wage $w$ which a landlord would like to evade, and hire only workers from the backward caste with the lower reservation wage $w_{B}$. However, both the advanced and the backward caste unions contest this minimum wage against the common employer, as well as against each other to increase the employment share for members within each union.

Such a wage contestation model between two groups of workers for a higher share of employment at a mandated minimum wage provides some interesting propositions. First, an increase in the reservation wage of either group of workers benefits the other group in terms of a higher share of employment at the minimum wage $w$. Second, an increase in the minimum wage $w$ itself benefits workers of the advanced caste as the expense of the backward caste in terms of a higher employment share. In order to understand these propositions in a parsimonious way, Dasgupta's model assumes the minimum wage to belong within the range of the maximum wage that a landlord is willing to pay a worker and the reservation wage of the advanced caste, or $w \in\left[w_{A}, \bar{W}\right]$. Workers belonging to each caste invest a fraction of the difference between the minimum wage and their reservation wage to contest non-cooperatively against each other, and against the landlord for a higher employment share. Since, $w-w_{A}<w-w_{B}$, the union representing the backward caste workers contest the minimum wage relatively more intensely.

In Dasgupta's framework above, consider now the case of an EGS that not only guarantees a wage but also employment to workers of either caste. Depending on the EGS wage, $w^{e}$, relative to the reservation wage of the two groups of workers we can sketch some cursory results:

(i) $w^{e}<w_{B}<w_{A}<\bar{W}$ : This is a trivial case where the institution of an EGS at a wage lower than the reservation wage of the backward caste workers has no effect on class conflict. Both 
unions will still invest in contesting the other and the landlord for a higher employment share at the agricultural wage $\bar{W}$.

(ii) $w_{B} \leq w^{e}<w_{A}<\bar{W}$ : When the EGS wage is greater than or equal to the reservation wage of the backward caste, the advanced caste benefits in terms of a higher employment share in agricultural work. The result follows from the fact that the union representing the backward caste will invest less in contesting the agricultural wage both because the gap between $\bar{W}-w^{e}$ is smaller and they can also find guaranteed EGS employment at $w^{e} \geq w_{B}$.

(iii) $w_{B}<w_{A} \leq w^{e}<\bar{W}$ : When the EGS wage is greater than or equal to the reservation wage of the advanced class workers, both unions reduce their investment in contesting the agricultural wage (with a relatively greater reduction for the backward caste workers). This situation also benefits the advanced caste in terms of a higher share of employment in agricultural work.

Thus an EGS has the potential to attract backward class workers and reduce inter-caste conflict but it also has the potential for increasing the employment share of the advanced caste in agricultural work. Nevertheless, extension of this basic model to a situation where unions representing the advanced and backward classes contest the agricultural wage in the presence of seasonal labor markets (in the lean as well as the peak) requires accounting for the trade-off of employment shares across the two seasons by the unions. In such a situation, reduction in inter-caste conflict during the lean season thanks to an EGS, specially case (iii) above, might well imply an escalation of conflict in the peak season if unions can divert resources saved in the lean season towards intensifying contestation of the agricultural wage in the peak. Perhaps more interesting is the case where absent collective bargaining laws, an EGS by providing a threat point can induce lobby formation amongst workers to negotiate higher wages with landlords. Needless to say, a formal analysis of the above is beyond the scope of this paper.

Aside from selected areas in the States of Kerala and Tamil Nadu, collective bargaining laws in rural India are seldom enforced, and workers have little recourse to contesting the mandated minimum wage. Yet, as Osmani (1991) notes, agricultural wages in rural India are sometimes higher than the competitive wage, and more interestingly workers resist this wage to be pushed down to the competitive level even in the presence of unemployment.

Implicit Contracts: Osmani (1991) models a situation where workers bid for a wage from a given distribution of wages, and an individual worker's wage bid depends on his perception of the probability of finding employment at that wage. The probability of finding employment 
for an individual worker depends, in turn, on how many workers actually bid a lower wage. In other words, the probability of finding employment for an individual worker depends on the wage bids by all workers. Thus an individual worker's payoff $(P)$ from a wage bid $\left(w_{i}\right)$ equals

$$
P_{i}(\tilde{w})=\theta_{i}(\tilde{w}) w_{i}+\left(1-\theta_{i}(\tilde{w}) c_{i}\right.
$$

where $\tilde{w}$ is the distribution of wage bids, $\theta_{i}$ is the probability of finding employment and $c_{i}$ is the opportunity income for this worker. Assuming all workers are identical and have the same opportunity income, a non-cooperative infinite period game with punitive actions in the future (trigger strategy) by workers against an individual who undercuts the equilibrium wage in any given period yields a Nash equilibrium wage that is higher than the competitive one (which equals the opportunity income, $c$, of the workers). Needless to say, the afore-mentioned equilibrium Nash outcome generates random involuntary unemployment for any worker at any given period. Yet, and because of the trigger strategy, no worker has the incentive to undercut the ongoing wage. In this case, institution of an EGS that pays the involuntarily unemployed a little more than the opportunity income $c$ will lead to an upward pressure on the agricultural wage as all workers adjust their wage bids upward.

Co-existence of Permanent and Casual Contracts in both Seasons: Based on the observation that in some areas of rural India, permanent and casual contracts co-exist in both the lean and the peak season, Mukherjee and Ray (1995) and Pal (2002) posit that the existence of tied labor contracts are an outcome of landlord's minimizing hiring costs in the casual market in each season. In other words, labor hoarding through tied contracts is a way to circumvent high casual season labor costs. The situation considered (see Pal (2002), for instance) is one where casual wages are low in the lean season and high in the peak season in a seasonal labor market. If casual wages are very low in the lean season then the rural labor market would be characterized by just a competitive casual labor market in each season. However, as lean season competitive wages increase and/or the anticipated casual wage in the peak season is very high, landlords find it cheaper to offer tied labor contracts to some laborers across both seasons. In equilibrium the permanent wage in each season is greater than the casual wage in the lean season but lower than the casual wage in the peak season. In other words, $w_{c}^{\text {lean }}<w_{p}<w_{c}^{\text {peak }}$ where $w_{p}$ is the permanent wage in each season and $w_{c}^{\text {lean }}$ and $w_{c}^{\text {peak }}$ are the casual wages in the lean and the peak season respectively. In this case, an EGS that offers guaranteed employment at a wage greater than the lean season casual wage will induce landlords to favor more permanent contracts as laborers would refuse to participate in the lean season casual labor market for any wage less than the EGS wage. 


\section{Conclusion}

This paper examines the labor and output market responses to a productive rural public works program and determines the optimum compensation to program employees. By accounting for the seasonality in agricultural production and the institution of permanent labor contracts, we have shown that technological change and productivity increases in EGS programs tend to make laborers better-off as compared to a direct increase in the wage paid at the relief program. Further, an optimal wage that maximizes expected agricultural output may be in conflict with the one that maximizes the expected lifetime utility of laborers. Trade-offs thus exist between different policy objectives. In the event where the elasticity of the EGS input with respect to permanent laborers is high, a specific subsidy targeted towards the hiring of permanent laborers best serves the twin objectives of increased expected agricultural productivity and increased welfare for the laborers. Finally, we extend our analysis to account for the impact of EGS programs on a number of other labor hiring mechanisms and point out that an EGS by introducing contestability in the agricultural labor market can yield a host of interesting implications for the wage and employment patterns of the rural poor. 


\section{Appendix A}

\section{A.1: Relationship between Permanent and Casual Laborers.}

An individual landlord maximizes peak season profit, for a given number of permanent laborers, to choose the number of casual laborers, i. e.,

$$
\max _{L_{C}^{i}} g\left(\bar{Q}_{G}\right) H\left(A \beta L_{P}^{i}, L_{P}^{i}+L_{C}^{i}\right)-w_{C}^{i} L_{C}^{i} ; \quad \text { s.t } \quad L_{C}^{i} \leq l_{C}^{i}\left(w_{C}^{1}, \ldots \ldots, w_{C}^{N}\right)
$$

Therefore,

$$
w_{C}=g\left(\bar{Q}_{G}\right) H_{2}\left(A \beta L_{P}^{i}, L_{P}^{i}+L_{C}^{i}\right)
$$

Totally differentiating the above equation yields,

$$
\frac{\partial L_{C}^{i}}{\partial w_{C}}=\frac{1}{g\left(\bar{Q}_{G}\right) H_{22}}<0
$$

and

$$
\frac{\partial L_{C}^{i}}{\partial L_{P}^{i}}=-\frac{\left(-\alpha N g^{\prime} H_{2}+g A \beta H_{21}+g H_{22}\right)}{g H_{22}}
$$

Since $H(\cdot, \cdot)$ exhibits constant returns to scale, we utilize the fact that $L_{P}^{i} H_{21}+L_{C}^{i} H_{22}=0$ and noting that $-\frac{\alpha N g^{\prime} L_{P}^{i}}{g}=\epsilon_{L_{P}^{i}}^{g}<0$ is the elasticity of the EGS input with respect to permanent labor while $\frac{H_{2}}{H_{22} L_{C}^{i}}=\epsilon_{L_{C}^{i}}^{H_{2}}<0$. Therefore,

$$
\frac{\partial L_{C}^{i}}{\partial L_{P}^{i}}=-\frac{\epsilon_{L_{P}^{i}}^{g}}{\epsilon_{L_{C}^{i}}^{H_{2}}} \frac{L_{C}^{i}}{L_{P}^{i}}+A \beta \frac{L_{C}^{i}}{L_{P}^{i}}-1
$$

Since $N L_{P}^{i}+N L_{C}^{i}=\mathcal{L}$ substituting above yields

$$
\frac{\partial L_{C}^{i}}{\partial L_{P}^{i}}=\left[-\frac{\epsilon_{L_{P}^{i}}^{g}}{\epsilon_{L_{C}^{i}}^{H_{2}}}+A \beta\right]\left[\frac{\mathcal{L}}{N L_{P}^{i}}-1\right]-1
$$

Thus in addition to a low value of $\epsilon_{L_{P}^{i}}^{g}$ and high values of $A$ and $\beta$, the larger the ratio of the total labor force to the total number of tied contracts offered, the greater is the possibility that permanent and casual laborers are complements of one another.

It remains to be shown that if $H\left(A \beta L_{P}^{i}, L_{a}^{i}\right)$ exhibits constant returns to scale then $L_{P}^{i} H_{21}+L_{C}^{i} H_{22}=0$. Consider the following Cobb-Douglas form for $H(\cdot, \cdot): Q_{H}=\left(A \beta L_{P}\right)^{\phi}\left(L_{P}+L_{C}\right)^{(1-\phi)}$. Therefore, $\frac{\partial Q_{H}}{\partial L_{P}}=\frac{\phi Q_{H}}{L_{P}}+\frac{(1-\phi) Q_{H}}{\left(L_{P}+L_{C}\right.}$ and $\frac{\partial Q_{H}}{\partial L_{C}}=\frac{(1-\phi) Q_{H}}{\left(L_{P}+L_{C}\right)}$. As a result, $L_{P} \frac{\partial Q_{H}}{\partial L_{P}}+L_{C} \frac{\partial Q_{H}}{\partial L_{C}}=0$. Again, $\frac{\partial^{2} Q_{H}}{\partial\left(L_{C}\right)^{2}}$ (equivalent to $H_{22}$ ) equals $-\frac{\phi(1-\phi) Q_{H}}{\left(L_{P}+L_{C}\right)^{2}}$ and $\frac{\partial^{2} Q_{H}}{\partial L_{C} \partial L_{P}}$ (equivalent to $H_{21}$ ) equals $\frac{\phi(1-\phi) Q_{H}}{\left(L_{P}+L_{C}\right)\left(L_{P}\right)}-\frac{\phi(1-\phi) Q_{H}}{\left(L_{P}+L_{C}\right)^{2}}$. Consequently, $L_{C} H_{22}+L_{P} H_{21}=0$.

Finally, totally differentiating equation (6) and substituting for $\frac{\partial L_{C}^{i}}{\partial L_{P}^{i}}$ we have

$$
\begin{aligned}
\frac{d w_{C}}{d L_{P}^{i}} & =-\frac{1+\frac{\partial L_{C}^{i}}{\partial L_{P}^{i}}}{(N-1) \frac{\partial L_{C}^{j}}{\partial w_{C}}+\frac{\partial L_{C}^{i}}{\partial w_{C}}}=-\frac{\left[-\frac{\epsilon_{L_{P}^{i}}^{g}}{\epsilon_{L_{C}^{i}}^{H_{2}}} \frac{L_{C}^{i}}{L_{P}^{i}}+A \beta \frac{L_{C}^{i}}{L_{P}^{i}}\right]}{(N-1) \frac{\partial L_{C}^{j}}{\partial w_{C}}+\frac{\partial L_{C}^{i}}{\partial w_{C}}} \\
\text { and } & \frac{1}{d\left(L_{P}^{i}\right)^{2}}=-\frac{1}{\left(N g H_{22}\right)^{2}}\left[-\frac{\mathcal{L} N g H_{22}}{\left(L_{P}^{i}\right)^{2}}\left(1+\epsilon_{L_{P}^{i}}^{g}\right)+\frac{2 N\left(\alpha N g^{\prime}\right)^{2} H_{2}}{g}-N(\alpha N)^{2} g^{\prime \prime} H_{2}-\frac{\alpha N g^{\prime} L_{C}^{i}}{L_{P}^{i}}\right]>(<) 0
\end{aligned}
$$


Further,

$$
\begin{aligned}
\frac{d}{d \beta}\left(\frac{d w_{C}}{d L_{P}^{i}}\right) & =-\frac{A \alpha N g^{\prime} H_{21} L_{P}^{i}}{N\left(g H_{22}\right)^{2}}<0 \\
\text { and } & \\
\frac{d}{d \alpha}\left(\frac{d w_{C}}{d L_{P}^{i}}\right) & =\frac{-1}{\left(N g H_{22}\right)^{2}}\left[N^{2} g^{\prime} H_{2}\left(1+\epsilon_{Q_{G}}^{g^{\prime}}\right)-\frac{N H_{2} \alpha N\left(g^{\prime}\right)^{2} L_{G}}{g H_{22}}-\left(1+\frac{L_{C}^{i}}{L_{P}^{i}}\left(1-\frac{\left|\epsilon_{L_{P}^{i}}^{g}\right|}{\left|\epsilon_{L_{C}^{i}}^{H_{2}}\right|}\right)\right) N g^{\prime} L_{G} H_{22}\right]
\end{aligned}
$$

The right hand side of the above equation is negative if (i) $\left|\epsilon_{Q_{G}}^{g^{\prime}}\right| \geq 1$ and (ii) $\frac{d w_{C}}{d L_{P}^{i}}>0$.

\section{A.2: Acceptability and Incentive-Compatibility.}

First, define $\hat{U}=U(\bar{w})+\rho \int_{\underline{A}}^{M} U\left(w_{C}\right) f(A) d A$ and rewrite equations (7) and (8) as

$$
\left[1-(1-p) \rho^{2}\right] V_{*}=p W_{*}+(1-p) \hat{U}
$$

and

$$
\left[1-(1-q) \rho^{2}\right] W_{*}=(1+\rho) U\left(w_{P}\right)+\rho^{2} q V_{*} .
$$

Now solving the above two equations simultaneously from the matrix below

$$
\left[\begin{array}{cc}
\left(1-(1-p) \rho^{2}\right) & -p \\
-\rho^{2} q & \left(1-(1-q) \rho^{2}\right)
\end{array}\right]\left[\begin{array}{c}
V_{*} \\
W_{*}
\end{array}\right]=\left[\begin{array}{c}
(1-p) \hat{U} \\
U\left(w_{P}\right)+\hat{U}
\end{array}\right]
$$

we get

$$
V_{*}=\frac{1}{|\mathcal{Q}|}\left[p(1+\rho) U\left(w_{P}\right)+(1-p)\left(1-(1-q) \rho^{2}\right) \hat{U}\right]
$$

and

$$
W_{*}=\frac{1}{|\mathcal{Q}|}\left[\left(1-(1-p) \rho^{2}\right)(1+\rho) U\left(w_{P}\right)+\rho^{2} q(1-p) \hat{U}\right],
$$

where $|\mathcal{Q}|=\left(1-\rho^{2}\right)\left[\left(1-\rho^{2}\right)+\rho^{2}(q+p(1-q))\right]>0$. Therefore the acceptability constraint $\left(W_{*} \geq V_{*}\right)$ implies that $(1+\rho) U\left(w_{P}\right) \geq \hat{U}$. Now define the lifetime utility of a reneger as

$$
R_{*}=\frac{\tilde{p}}{\left(1-(1-\tilde{p}) \rho^{2}\right)} W_{*}+\frac{(1-\tilde{p})}{\left(1-(1-\tilde{p}) \rho^{2}\right)} \hat{U}
$$

Therefore,

$$
\begin{aligned}
V_{*}-R_{*} & =\frac{\left(1-\rho^{2}\right) \mu p}{\left(1-(1-p) \rho^{2}\right)\left(1-(1-\tilde{p}) \rho^{2}\right)}\left[W_{*}-\frac{\hat{U}}{\left(1-\rho^{2}\right)}\right] \geq 0, \\
W_{*}-R_{*} & =\frac{\left(1-\rho^{2}\right)(1-\tilde{p})}{\left(1-(1-\tilde{p}) \rho^{2}\right)}\left[W_{*}-\frac{\hat{U}}{\left(1-\rho^{2}\right)}\right] \geq 0 .
\end{aligned}
$$

To show that the incentive-compatibility constraint implies the acceptability constraint we rewrite the incentive-compatibility constraint, $\left(U\left(w_{P}\right)+\rho W_{*} \geq U\left(w_{C}^{+}\right)+\rho R_{*}\right)$, as

$$
\nu\left[(1+\rho) U\left(w_{P}\right)-\hat{U}\right] \geq\left[U\left(w_{C}^{+}\right)-U\left(w_{P}\right)\right] .
$$

Note that the right hand side of the above equation is strictly positive and therefore the left hand side, denoting the acceptability constraint and given by $(1+\rho) U\left(w_{P}\right)-\hat{U}$, is also $>0$. 
Rearranging the incentive-compatibility constraint we get,

$$
\left[U\left(w_{P}\right)-U(\bar{w})\right] \geq \frac{1}{\nu}\left[U\left(w_{C}^{+}\right)-U\left(w_{P}\right)\right]+\rho\left[\int_{\underline{A}}^{M} U\left(w_{C}\right) f(A) d A-U\left(w_{P}\right)\right] .
$$

Again, since the right hand side of the above equation is strictly positive and as a result, $U\left(w_{P}\right)>U(\bar{w})$ or $w_{P}>\bar{w}$.

We now need to show that $w_{P}<\int_{\underline{A}}^{M} w_{C} f(A) d A$. Consider the incentive-compatibility constraint from the beginning of the lean season. Landlords, in this case must choose to offer a permanent wage such that

$$
(1+\rho) U\left(w_{P}\right)+\rho^{2} q V_{*}+(1-q) \rho^{2} W_{*} \geq U\left(w_{P}\right)+\rho \int_{\underline{A}}^{M} U\left(w_{C}\right) f(A) d A+\rho^{2} R_{*}
$$

Substituting for $W_{*}, V_{*}$ and $R_{*}$ we get

$$
\begin{gathered}
(1+\nu(1+\rho)) U\left(w_{P}\right) \geq(1+\nu \rho) \int_{\underline{A}}^{M} U\left(w_{C}\right) f(A) d A, \\
U\left(w_{P}\right) \geq \frac{(1+\nu \rho)}{(1+\nu(1+\rho))} \int_{\underline{A}}^{M} U\left(w_{C}\right) f(A) d A .
\end{gathered}
$$

Define

$$
U\left(\tilde{w_{C}}\right)=\frac{1+\nu \rho}{1+\nu(1+\rho)} U\left(w_{C}\left(L_{P}^{i}, A, \bar{Q}_{G}, \beta\right)\right)+\frac{1+\nu \rho}{1+\nu(1+\rho)} U(0) .
$$

Noting that $U$ is strictly concave and applying Jensen's inequality we have,

$$
\tilde{w}_{C}<\frac{1+\nu \rho}{1+\nu(1+\rho)} w_{C}\left(L_{P}^{i}, A, \bar{Q}_{G}, \beta\right)<w_{C}\left(L_{P}^{i}, A, \bar{Q}_{G}, \beta\right)
$$

since $\frac{(1+\nu \rho)}{(1+\nu(1+\rho))}<1$. In addition, since $\int_{\underline{A}}^{M} U\left(\tilde{w_{C}}\right) f(A) d A=U\left(w_{P}\right)$ if the incentive-compatibility constraint is binding, invoking Jensen's inequality once again results in

$$
w_{P}<\int_{\underline{A}}^{M} \tilde{w_{C}}\left(L_{P}^{i}, A, \bar{Q}_{G}, \beta\right) f(A) d A<\int_{\underline{A}}^{M} w_{C}\left(L_{P}^{i}, A, \bar{Q}_{G}, \beta\right) f(A) d A .
$$

A.3: $\frac{\partial \nu}{\partial \mathbf{L}_{\mathbf{P}}^{i}}<\mathbf{0 .}$

First note that $\nu$ is given by

$$
\nu=\frac{\rho\left(1-\rho^{2}\right)(1-\tilde{p})\left(1-\rho^{2}(1-p)\right)}{|\mathcal{Q}|\left(1-(1-\tilde{p}) \rho^{2}\right)} .
$$

Substituting for $|\mathcal{Q}|$ and in the above equation and defining $u=\rho(1-\tilde{p})\left(1-(1-p) \rho^{2}\right)$ and $v=$ $\left(1-(1-\tilde{p}) \rho^{2}\right)\left[\left(1-\rho^{2}\right)+\rho^{2}(q+p(1-q))\right]$ we get

$$
\begin{aligned}
\frac{\partial u}{\partial p} & =-(1-\mu)\left(1-(1-p) \rho^{2}\right)+(1-\tilde{p}) \rho^{2}>(<) 0 \\
\frac{\partial^{2} u}{\partial p^{2}} & =-2(1-\mu) \rho^{2}<0 \\
\frac{\partial v}{\partial p} & =\left[\left(1-\rho^{2}\right)+\rho^{2}(q+p(1-q)](1-\mu) \rho^{2}+\left(1-(1-\tilde{p}) \rho^{2}\right) \rho^{2}(1-q)>0\right. \\
\frac{\partial^{2} v}{\partial p^{2}} & =2(1-q)(1-\mu) \rho^{4}>0
\end{aligned}
$$


Now

$$
\frac{\partial \nu}{\partial p}=\frac{1}{v^{2}}\left[v \frac{\partial u}{\partial p}-u \frac{\partial v}{\partial p}\right]
$$

Therefore $\frac{\partial \nu}{\partial p}<0$ if $\mu \rightarrow 1$.

Again,

$$
\frac{\partial^{2} \nu}{\partial p^{2}}=\frac{1}{v^{2}}\left(v \frac{\partial^{2} u}{\partial p^{2}}-u \frac{\partial^{2} v}{\partial p^{2}}\right)-\frac{2}{v} \frac{\partial \nu}{\partial p} \frac{\partial v}{\partial p}<0 .
$$

if $\frac{\partial v}{\partial p} \rightarrow 0$ which is the case if (i) $\mu \rightarrow 1$ and (ii) $q \rightarrow 1$.

Now

$$
\begin{aligned}
\frac{\partial p}{\partial L_{P}^{i}} & =\frac{q N}{\left(1-(1-q) N L_{P}^{i}\right)}>0 \\
\frac{\partial^{2} p}{\partial\left(L_{P}^{i}\right)^{2}} & =\frac{2 q(1-q) N^{2}}{\left(1-(1-q) N L_{P}^{i}\right)^{3}}>0 .
\end{aligned}
$$

Therefore $\frac{\partial \nu}{\partial L_{P}^{i}}<0$ and $\frac{\partial^{2} \nu}{\partial\left(L_{P}^{i}\right)^{2}}<0$.

\section{Appendix B}

\section{B.1: Market Responses to an EGS program.}

Totally differentiating equations (12) and (14) after substituting for $\lambda$ from equation (13) into equation (12) and using Cramer's rule we get

$$
\left[\begin{array}{cc}
Z & -Y \\
N & -M
\end{array}\right]\left[\begin{array}{l}
d L_{P} \\
d w_{P}
\end{array}\right]=\left[\begin{array}{c}
-S d \alpha-R d \beta \\
-J d \bar{w}
\end{array}\right]
$$

where

$$
\begin{aligned}
Z= & \frac{d^{2} E Q_{H}^{i}}{d\left(L_{P}^{i}\right)^{2}}-\frac{d^{2} T C^{2}}{d\left(L_{P}^{i}\right)^{2}}-\Psi_{P} \\
Y= & \frac{(1+\rho)}{(1-\rho)}-\lambda(1+\rho) U^{\prime}\left(w_{P}\right) \frac{\partial \nu}{\partial L_{P}^{i}}\left[1+\frac{\epsilon_{w_{P}}^{\lambda}}{\epsilon_{w_{P}}^{U}}\right]>0 \\
M= & (1+\nu(1+\rho)) U^{\prime}\left(w_{P}\right)>0 \\
N= & \nu \rho \int_{\underline{A}}^{M} U^{\prime}\left(w_{C}\right) \frac{d w_{C}}{d L_{P}^{i}} f(A) d A-\left[W_{*}-V_{*}\right] \frac{\partial \nu}{\partial L_{P}^{i}}>0 \\
R= & \frac{\rho}{(1-\rho)} \int_{\underline{A}}^{M}\left[A g H_{1} \frac{L_{C}^{i}}{\mathcal{L}} \epsilon_{L_{P}^{i}}^{H_{1}}+A g H_{1}\left(1+\epsilon_{L_{P}^{i}}^{g}\right)+\frac{d w_{C}}{d \beta}-\frac{d}{d \beta}\left(\frac{d w_{C}}{d L_{P}^{i}}\right)\left(\frac{\mathcal{L}}{N}-L_{P}^{i}\right)\right] f(A) d A \\
& -\lambda \rho \int_{\underline{A}}^{M} U^{\prime}\left(w_{C}\right) \frac{d w_{C}}{d \beta} \frac{\partial \nu}{\partial L_{P}^{i}} f(A) d A-\lambda\left[U^{\prime \prime}\left(w_{C}^{+}\right) \frac{d w_{C}^{+}}{d \beta} \frac{d w_{C}^{+}}{d L_{P}^{i}}+U^{\prime}\left(w_{C}^{+}\right) \frac{d}{d \beta}\left(\frac{d w_{C}^{+}}{d L_{P}^{i}}\right)\right] \\
& -\lambda \nu \rho \int_{\underline{A}}^{M}\left[U^{\prime \prime}\left(w_{C}\right) \frac{d w_{C}}{d \beta} \frac{d w_{C}}{d L_{P}^{i}}+U^{\prime}\left(w_{C}\right) \frac{d}{d \beta}\left(\frac{d w_{C}}{d L_{P}^{i}}\right)\right] f(A) d A
\end{aligned}
$$




$$
\begin{aligned}
S= & \frac{\rho}{(1-\rho)} \int_{\underline{A}}^{M}\left[A \beta g^{\prime} L_{G} H_{1}+N g^{\prime} H\left(1+\epsilon_{Q_{G}}^{g^{\prime}}\right)+\frac{d w_{C}}{d \alpha}-\frac{d}{d \alpha}\left(\frac{d w_{C}}{d L_{P}^{i}}\right)\left(\frac{\mathcal{L}}{N}-L_{P}^{i}\right)\right] f(A) d A \\
& -\lambda \rho \int_{\underline{A}}^{M} U^{\prime}\left(w_{C}\right) \frac{d w_{C}}{d \alpha} \frac{\partial \nu}{\partial L_{P}^{i}} f(A) d A-\lambda\left[U^{\prime \prime}\left(w_{C}^{+}\right) \frac{d w_{C}^{+}}{d \alpha} \frac{d w_{C}^{+}}{d L_{P}^{i}}+U^{\prime}\left(w_{C}^{+}\right) \frac{d}{d \alpha}\left(\frac{d w_{C}^{+}}{d L_{P}^{i}}\right)\right] \\
& -\lambda \nu \rho \int_{\underline{A}}^{M}\left[U^{\prime \prime}\left(w_{C}\right) \frac{d w_{C}}{d \alpha} \frac{d w_{C}}{d L_{P}^{i}}+U^{\prime}\left(w_{C}\right) \frac{d}{d \alpha}\left(\frac{d w_{C}}{d L_{P}^{i}}\right)\right] f(A) d A \\
J= & \nu U^{\prime}(\bar{w})>0
\end{aligned}
$$

where

$$
\begin{aligned}
\frac{d^{2} E Q_{H}^{i}}{d\left(L_{P}^{i}\right)^{2}}= & \frac{\rho}{(1-\rho)} \int_{\underline{A}}^{M}\left[(A \beta)^{2} g H_{11}-2 A \beta \alpha N g^{\prime} H_{1}+(\alpha N)^{2} g^{\prime \prime} H\right] f(A) d A \\
\frac{d^{2} T C^{2}}{d\left(L_{P}^{i}\right)^{2}}= & -\frac{\rho}{(1-\rho)} \int_{\underline{A}}^{M}\left[\frac{d w_{C}}{d L_{P}^{i}}\left(2+\epsilon_{L_{P}^{i}}^{\left(w_{C}\right)^{\prime}}\right)+\frac{d^{2} w_{C}}{d\left(L_{P}^{i}\right)^{2}}\left(\frac{\mathcal{L}}{N}\right)\right] f(A) d A \\
\Psi_{P}= & -\Omega \frac{\partial \lambda}{\partial L_{P}^{i}}-\lambda\left[W_{*}-V_{*}\right] \frac{\partial^{2} \nu}{\partial\left(L_{P}^{i}\right)^{2}}+2 \lambda \rho \frac{\partial \nu}{\partial L_{P}^{i}} \int_{\underline{A}}^{M} U^{\prime}\left(w_{C}\right) \frac{d w_{C}}{d L_{P}^{i}} f(A) d A \\
& +\lambda U^{\prime \prime}\left(w_{C}^{+}\right)\left(\frac{d w_{C}^{+}}{d L_{P}^{i}}\right)^{2}\left[1-\frac{\epsilon_{L_{P}^{i}}^{\left(w_{C}^{+}\right)^{\prime}}}{r_{w_{C}^{+} \epsilon_{L_{P}^{i}}^{w^{+}}}}\right]+\lambda \nu \rho \int_{\underline{A}}^{M}\left\{U^{\prime \prime}\left(w_{C}\right)\left(\frac{d w_{C}}{d L_{P}^{i}}\right)^{2}\left[1-\frac{\epsilon_{L_{P}^{i}}^{\left(w_{C}\right)^{\prime}}}{r_{w_{C}} \epsilon_{L_{P}^{i}}^{w_{C}}}\right]\right\} f(A) d A
\end{aligned}
$$

where $\epsilon_{L_{P}^{i}}^{(j)^{\prime}}=\frac{d^{2} j}{d\left(L_{P}^{i}\right)^{2}} \frac{L_{P}^{i}}{d L_{P}^{i}}>0, j=w_{C}^{+}, w_{C} ; \epsilon_{n}^{m}$ is the elasticity of $m$ with respect to $n, m=U, g, g^{\prime}, w_{C}, w_{C}^{+}, \lambda$; $n=L_{P}^{i}, Q_{G}, w_{P}$ and $r_{j}$ is the relative risk aversion with respect to the casual wage. It can easily be checked that $\frac{\partial \lambda}{\partial n}, n=L_{P}^{i}, w_{P}$ are both positive.

The sign of $Z$ is in general indeterminate. We shall assume, however, that $\frac{d^{2} Q_{H}^{i}}{d\left(L_{P}^{i}\right)^{2}}-\frac{d^{2} T C^{2}}{d\left(L_{P}^{i}\right)^{2}}-\Psi_{P}$ is negative by the second order condition of profit maximization. With the determinant of the above matrix $|\mathcal{H}|=-Z M+Y N>0$, we have therefore:

(i) $\frac{d L_{P}^{i}}{d \bar{w}}<0, \frac{d w_{P}}{d \bar{w}}>0$ and $\frac{d w_{C}}{d \bar{w}}>0$ iff $\left|\epsilon_{L_{P}^{i}}^{g}\right|>\epsilon_{L_{P}^{i}}^{\mathcal{E} Q_{P}}$.

(ii) $\frac{d L_{P}^{i}}{d \alpha}>0, \frac{d w_{P}}{d \alpha}>0$ and $\frac{d w_{C}}{d \alpha}>0$.

(iii) $\frac{d L_{P}^{i}}{d \beta}>0, \frac{d w_{P}}{d \beta}>0$ and $\frac{d w_{C}}{d \beta}>0$.

\section{Appendix B.2: Determination of the Optimum Wage.}

Optimum wage consistent with the the maximization of the welfare of the laborers is derived by totally differentiating

$$
V_{*}=\frac{1}{|\mathcal{Q}|}\left[p(1+\rho) U\left(w_{P}\right)+(1-p)\left(1-(1-q) \rho^{2}\right) \hat{U}\right]
$$

with respect to $\bar{w}_{v}$ we get

$$
\begin{aligned}
\frac{d V_{*}}{d \bar{w}}= & \frac{1}{|\mathcal{Q}|}\left\{p(1+\rho) U^{\prime}\left(w_{P}\right) \frac{d w_{P}}{d \bar{w}}+(1-p)\left(1-(1-q) \rho^{2}\right)\left[U^{\prime}(\bar{w})+\rho \int_{\underline{A}}^{M} U^{\prime}\left(w_{C}\right) \frac{d w_{C}}{d L_{P}} \frac{d L_{P}}{d \bar{w}} f(A) d A\right]\right\} \\
& +\frac{1}{|\mathcal{Q}|}(1+\rho) U\left(w_{P}\right)-\left(1-(1-q) \rho^{2}\right)\left[u(\bar{w})++\rho \int_{\underline{A}}^{M} U\left(w_{C}\right) f(A) d A\right] \frac{d p}{d L_{P}} \frac{d L_{P}}{d \bar{w}} \\
& -\frac{1}{\left|\mathcal{Q}^{2}\right|}\left\{p(1+\rho) U\left(w_{P}\right)+(1-p)\left(1-(1-q) \rho^{2}\right)[\hat{U}]\left(1-\rho^{2}\right) \rho^{2}(1-q) \frac{d p}{d L_{P}} \frac{d L_{P}}{d \bar{w}}=0\right.
\end{aligned}
$$


Rearranging the above equation and substituting for $V_{*}$ yields equation (16). 


\section{References}

Ahmad, Q. K. and Hossain, M. (1985); "An evaluation of Selected Policies and Programmes for the Alleviation of Rural Poverty in Bangladesh"; in Islam, R (ed.), Strategies for Alleviating Poverty in Rural Asia. (Bangkok: ILO).

Alamgir, M. (1983); "A Review of the Public Rural Works Programme of Bangladesh 1960 - 78"; The Bangladesh Development Studies, 11, pp. 13 - 40.

Bardhan, P. K. (1979); "Wages and Unemployment in a Poor Agrarian Economy: A Theoretical and Empirical Analysis"; Journal of Political Economy, 87, pp. 479 - 500.

(1983); "Labor-Tying in a Poor Agrarian Economy: A Theoretical and Empirical Analysis"; Quarterly Journal of Economics, 98, pp. 501 - 514.

— and Rudra, A. (1981); "Terms and Conditions of Labor Contracts in Agriculture: Results of a Survey in West Bengal, 1979"; Oxford Bulletin of Economics and Statistics, 43, pp. 89 - 111.

Basu, Arnab K., Chau, Nancy H., and Kanbur, Ravi. (2009). "A Theory of Employment Guarantees: Contestability, Credibility and Distributional Concerns"; Journal of Public Economics, 93, pp 482-497.

Basu, Arnab K. and Chau, Nancy H. (2003). "Targeting Child Labor in Debt Bondage: Evidence Theory and Policy Prescriptions"; The World Bank Economic Review, 17, pp 255-281.

Basu, Arnab K. and Chau, Nancy H. (2004). "Exploitation of Child Labor and the Dynamics of Debt Bondage"; Journal of Economic Growth, 9, pp 209-238.

Basu, Arnab K. (2002); "Oligopsonistic Landlords, Segmented Labor Markets and the Persistence of Tied-Labor Contracts"; American Journal of Agricultural Economics, 84, pp. 438-453.

Basu, Kaushik. (1981); "Food for Work Programmes: Beyond Roads that get Washed Away"; Economic and Political Weekly, 16, pp. 37 - 40.

— (1982); "Food for Work. Some Economic and Political Consequences"; Review of Agriculture, Economic and Political Weekly, 17, pp. A9 - A14.

— (1990); "The Elimination of Endemic Hunger in South Asia: Some Policy Options"; in Drèze, J and Sen, A (eds.) The Political Economy of Hunger. Clarendon Press, Oxford.

Besley, T. (1990); "Means Testing Versus Universal Provision in Poverty Alleviation Programmes"; Economica, 57, pp. 119 - 129.

— and Coate, S. (1992); "Workfare versus Welfare: Incentive Arguments for Work Requirements in Poverty Alleviation Programs"; American Economic Review, 82, pp. 249 - 261.

Bhasin, Veena. (2004) "Economic Pursuits and Strategies of Survival among Damor of Rajasthan"; Journal of Human Ecology, 16, pp 1-16.

Binswanger, H. P, Khandker, S. R and Rosenzweig, M. R. (1993); "How Infrastructure and Financial Institutions affect Agricultural Output and Investment in India"; Journal of Development Economics, 41, pp. 337 - 366.

Braverman, A and Stiglitz, J. (1986); "Landlords, Tenants and Technological Innovations"; Journal of Development Economics, 23, pp. 313 - 332.

Chakraborty, Pinaki. (2007). "Implementation of the National Rural Employment Guarantee Act in India: Spatial Dimensions and Fiscal Implications"; Working paper No. 505, The Levy Institute of Bard College, Annandale-on-Hudson, NY. 
Dandekar, K and Sathe, M. (1980); "Employment Guarantee Scheme and Food for Work Programme"; Economic and Political Weekly, 15, pp. 707 - 713.

Dandekar, V. M. (1986); "Agriculture, Employment and Poverty"; Review of Agriculture, Economic and Political Weekly, 21, pp. A90 - A100.

Datt, G. and Ravallion, M. (1994); "Transfer Benefits from Public Works Employment: Evidence for Rural India"; The Economic Journal, 104, pp. 1346 - 1369.

Drèze, J. (1990); "Famine Prevention in India"; in Drèze, J and Sen, A. (eds.) The Political Economy of Hunger. Clarendon Press, Oxford.

Dasgupta, Indraneel. (2009). "Living' Wage, Class Conflict and Ethnic Strife"; Journal of Economic Behavior and Organization, 72, pp 750-765).

Deshingkar, Priya and John Farrington. (2006). "Rural Labour Markets and Migration in South Asia: Evidence from India and Bangladesh"; Background Paper for the World Development Report 2008.

http://siteresources.worldbank.org/INTWDR2008/Resources/2795087-1191427986785/DeshingkarP\&Farrington.pdf.

Dev, Mahendra. (1995). "India's (Maharashtra) Employment Guarantee Scheme: Lessons from Long Experience" in von Braun, Joachim (ed), Employment for Poverty Reduction and Food Security, International Food Policy Research Institute (IFPRI), Washington D.C., pp 108-143.

Eswaran, M and Kotwal, A. (1985); "A Theory of Two-Tier Labor markets in Agrarian Economies"; American Economic Review, 75, pp. 162 - 177.

Fan, Shenggen, Hazell, Peter and Thorat, Sukhdeo. (2000); "Government Spending, Growth and Poverty in Rural India"; American Journal of Agricultural Economics, 82, pp. 1038-1051.

Fields, Gary and Kanbur, Ravi. (2007); "Minimum Wages and Poverty with Income Sharing"; Journal of Economic Inequality, 5, pp 135-147.

Foster, J., J. Greer and Thorbecke, E. (1984); "A Class of Decomposable Poverty Measures"; Econometrica, 52, pp 761-776.

Genicot, Garance. (2002); "Bonded Labor and Serfdom: A Paradox of Voluntary Choice," Journal of Development Economics, 67, pp 101-127.

Harris, J. R and Todaro, M. P. (1970); "Migration, Unemployment and Development: A Two-Sector Analysis"; American Economic Review, 60, pp. 126-142.

India Rural Development Report (1999); National Institute for Rural Development, Hyderabad, India.

Jha, Raghbendra; Bhattacharyya, Sambit; Gaiha, Raghav and Shankar, Shylashri. (2009); "'Capture' of Anti-Poverty Programs: An Analysis of the National Rural Employment Guarantee Program in India"; Journal of Asian Economics 20, pp 456-464.

Khan, M. Ali. (1993); "Trade and Development in the presence of an Informal Sector: A Four-Factor Model"; in Basu, K, Majumdar, M and Mitra, T (eds.) Capital, Investment and Development. Blackwell Publishers, Cambridge, Massachusetts.

Lipton, Michael. (1996); "Success in Anti-Poverty"; Issues in Development, Discussion Paper 8, International Labour Organization, Geneva.

Mearns, Robin. (2000); "Access to Land in Rural India"; World bank Policy Research Working Paper, Number 2123, The World Bank, Washington, D. C. 
Motiram, Sripad. (2007); "Attached Labour Contracts in Agriculture: Results and Analysis from a Survey in South India"; Canadian Journal of Development Research, 28, pp 99-117.

Mukherjee, A. and Ray, Debraj. (1992); "Wages and Involuntary Unemployment in the Slack Season of a Village Economy"; Journal of Development Economics, 37, pp. 227 - 264.

— and —. (1995); "Labor Tying"; Journal of Development Economics, 47, pp. 207 - 239.

The National Rural Employment Guarantee Act of 2005. The Gazette of India, Ministry of Law and Justice, No. 48.

Narayana, N., Parikh, K and Srinivasan, T. (1988); "Rural Works Programs in India: Costs and Benefits"; Journal of Development Economics, 29, pp. 131 - 156.

Osmani, S. R. (1991); "Wage Determination in Rural Labor Markets: The Theory of Implicit Cooperation"; Journal of Development Economics, 34, pp. 3 - 23.

and Chowdhury, O. H. (1983); "Short Run Impacts of Food for Work Programme in Bangladesh"; The Bangladesh Development Studies, 11, pp. 135 - 190.

Pal, S. (2002). "Segmentation of Rural Labour Contracts: Some Further Evidence"; Bulletin of Economic Research, 54(2): 151-80.

Ravallion, M. (1991); "On the Coverage of public Employment Schemes for Poverty Alleviation"; Journal of Development Economics, 34, pp. 57 - 79.

_ (1990); "Market Responses to Anti-Hunger Policies: Effects on Wages, Prices and Employment"; in Drèze, J and Sen, A (eds.) The Political Economy of Hunger. Clarendon Press, Oxford.

— Datt, G. and Chaudhuri, S. (1993); "Does Maharashtra's "Employment Guarantee Scheme" Guarantee Employment?"; Economic Development and Cultural Change, 41, pp. 251 - 276.

Rawal, Vikas. (2006); "The Labour Process in Rural Haryana (India): A Field-Report from Two Villages"; Journal of Agrarian Change, 6, pp 538-583.

Sathe, M. D. (1991). "Rural Employment and Employment Guarantee Scheme in Maharashtra". Vijayanagar, Pune and Mahrashtra Development Group.

Shanmugam, T.R. and Vijayalakshmy, K. (2005); "Determinants of Agricultural Labour Participation in Organisation in India"; Agricultura Tropica et Subtropica, 38, pp 51-55.

Singh, Lakhwinder; Singh, Inderjeet and Ghuman, Ranjit Singh. (2007); "Changing Character of Rural Economy and Migrant Labour in Punjab"; Munich Personal RePEc Archive, Paper No. 6420. http://mpra.ub.uni-muenchen.de/6420/

Srivastava, Ravi. (2005); "Bonded Labour in India: Its Incidence and Pattern"; InFocus Programme on Promoting the Declaration on Fundamental Principles and Rights at Work, International Labour Office, Geneva.

Subbarao, K. (1999); "Public Works as an Anti-Poverty Program: An Overview of Cross-Country Experience"; American Journal of Agricultural Economics, 84(2), pp. 678-683.

Thomas, J. W. (1971); "The Rural Public Works Programme and Rural Development in East Pakistan"; in Falcon, W. P and Papanek, G. F. (eds.) Development Policy II: The Pakistan Experience. Harvard University Press, Cambridge, Massachusetts. 